ISSN: 2174-5609

DOI. https://doi.org/10.14198/INTURI2022.23.10

Tur Investigaciones

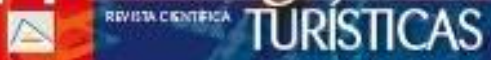

Cita bibliográfica: Cerdá Mansilla, E., Rubio, N., García Henche, B.y Campo, S. (2022). Airbnb y la turistificación de los barrios en las ciudades: un análisis de segmentación por barrios del alojamiento extrahotelero en Madrid. Investigaciones Turísticas (23), pp. 210-238 https://doi.org/10.14198/INTURI2022.23.10

\title{
Airbnb y la turistificación de los barrios en las ciudades: un análisis de segmentación por barrios del alojamiento extrahotelero en Madrid
}

Airbnb and the touristification of neighborhoods in cities: an analysis of neighborhood segmentation of extra-hotel accommodation in Madrid

Elena Cerdá-Mansilla (iD Universidad Autónoma de Madrid, España

elena.cerda@uam.es

Natalia Rubio (iD) Universidad Autónoma de Madrid, España

natalia.rubio@uam.es

Blanca García-Henche (iD) Universidad de Alcalá, España

blanca.garcia@uah.es

Sara Campo (iD) Universidad Autónoma de Madrid, España

sara.campo@uam.es

\section{RESUMEN}

La proliferación de plataformas peer to peer (P2P) de alojamiento turístico extrahotelero (Airbnb, Vrbo, HouseTrip, etc.) ha promovido la turistificación de muchos barrios en gran un número de ciudades, que se han visto afectados por un considerable incremento de la oferta de estos alojamientos. En este artículo se analizan los alojamientos turísticos extrahoteleros de Airbnb en el territorio de Madrid. Para medir el impacto de Airbnb en Madrid se realizan diversas agrupaciones de los distritos de la ciudad mediante análisis clúster en base a tres indicadores cuantitativos referidos a los alojamientos de la plataforma ( $\mathrm{n}$ - de alojamientos, $\mathrm{n}$ ㅇ de alojamientos $/ \mathrm{km}^{2}$ y precio medio de los alojamientos). Se complementa el análisis de los alquileres turísticos, agrupando los distritos en función del precio medio de los alquileres destinados a uso permanente (Fotocasa), a fin de tener una imagen más fidedigna de la vivienda de alquiler en la capital española. Por último, se sugieren distintas soluciones para la descongestión de determinados distritos, resaltando la posibilidad del uso de inteligencia artificial mediante algoritmos para una gestión eficaz de los destinos; así como se acentúa la importancia de guiar las actuaciones gubernamentales hacia la sostenibilidad del destino.

Palabras clave: P2P; Airbnb; turistificación; gentrificación; sostenibilidad. 


\section{ABSTRACT}

The proliferation of peer to peer (P2P) platforms for non-hotel tourist accommodation (Airbnb, HomeAway, HouseTrip, etc.) has promoted the touristification of many neighborhoods in a large number of cities, which have been affected by a considerable increase in the supply of this kind of accommodation. This article analyses Airbnb's non-hotel tourist accommodation in Madrid. Various groupings of the city's districts are made through cluster analysis to measure the impact of Airbnb in Madrid, based on three quantitative indicators related to the platform's accommodations (number of accommodations, number of accommodations / $\mathrm{km}^{\wedge} 2$ and average rental price). The analysis of tourist rentals is complemented with a grouping the districts according to the average rental price for permanent use (Fotocasa), in order to gain a more accurate picture of rented housing in the Spanish capital. Finally, different solutions are suggested for the decongestion of certain districts, highlighting the possibility of using artificial intelligence through algorithms for an effective management of destinations. Furthermore, the importance of guiding government actions towards the sustainability of the destination is emphasized.

Key words: P2P; Airbnb; touristification; gentrification; sustainability.

\section{INTRODUCCIÓN}

En España, el sector turístico supuso en 2019 el 12,4\% del PIB. En ese mismo año, el empleo del sector representó el 12,9\% de los empleos directos, con más de 2,72 millones de puestos de trabajo (INE, 2019a). Por otra parte, las llegadas de turistas internacionales a España supusieron más de 83,7 millones, siendo la segunda potencia mundial turística tras Francia $y$, también, ocupando el segundo puesto el gasto efectuado por los turistas, tras Estados Unidos, con cerca de 92.278 millones de euros (INE, 2019b). Además, también en ese año 2019, España fue el país más competitivo del mundo en términos turísticos, según recogió el 'Informe sobre Competitividad en Viajes y Turismo 2019' elaborado por el Foro Económico Mundial (World Economic Forum).

Según el World Travel Monitor de ITB, los viajes de los turistas europeos a países extranjeros aumentaron un 2,5\% de media en 2019 y el segmento que más creció fue el turismo urbano, con un fuerte incremento del $8 \%$ en los ocho primeros meses. Con una cuota de mercado global de cerca del 30 por ciento, las escapadas a la ciudad se ubicaron ligeramente detrás de las vacaciones de sol y playa, que registraron un aumento del $2 \%$ durante los primeros ocho meses.

Respecto al turismo urbano en Europa, según el Informe de 2019 de la ECM (European Cities Marketing), las ciudades europeas como Londres, París, Berlín, Roma, Estambul, Madrid y Barcelona, entre otras, resultaron ser los destinos turísticos más atractivos para los visitantes de todo el mundo; llegando a captar hasta 85 millones de turistas en el caso de Londres. Las estancias en ciudades europeas se mantuvieron sin cambios en 2018 respecto al año anterior, donde Londres también ocupaba el primer lugar seguida de París y Berlín. Si bien, en el top 5 figuraban dos ciudades españolas, Madrid y Barcelona, con una subida de pernoctaciones de $2,4 \%$ y $2,7 \%$ en casa caso.

Según Madrid Destino "empresa municipal dedicada a la gestión cultural, turística y de espacios y eventos" el perfil del turista que llega a la capital española es un visitante interesado 
por la cultura, los museos, la gastronomía, la vida nocturna y la hospitalidad española. Respecto al número de visitantes, la ciudad de Madrid registró en 2019 la llegada de 10,4 millones de visitantes ( $+2,1 \%$ respecto a 2018 ), de los cuales el $55 \%$ fueron internacionales y el $45 \%$ nacionales. Se alcanzó un gasto total de 10.451 millones $(+12,6 \%)$ y un gasto medio diario de 270 euros (+11\%).

Para entender el contexto turístico que enmarca a la capital española, se analiza, a continuación, la evolución de la oferta de plazas y la demanda de pernoctaciones en hoteles y apartamentos turísticos de la Comunidad en el período de 2001 a 2019. Los datos recogidos en la Tabla 1 muestran una evolución muy positiva de la oferta y la demanda, si bien el crecimiento de la demanda resulta superior al de la oferta, lo que ha contribuido en parte, a la proliferación y consolidación de plataformas peer to peer (P2P) de alojamiento turístico extrahotelero como Airbnb, HomeAway o HouseTrip, entre otras, que captan parte de esa demanda.

Si se realiza un análisis de la oferta alojativa madrileña, en función de las distintas tipologías de alojamiento (hotelero y apartamento turístico), se observa que los desajustes no afectan por igual a ambas tipologías de hospedaje. La oferta de plazas y la demanda de pernoctaciones que se registran en el período 2001-2019 presentan un crecimiento superior en la demanda de los alojamientos hoteleros y apartamentos turísticos en comparación con la oferta de ambos. Este desfase entre demanda y oferta permite entender en parte el auge de las plataformas P2P de alquiler de alojamientos extrahoteleros. Debe destacarse, además, que el desfase se acentúa en el caso de los alojamientos hoteleros, donde la diferencia entre demanda y oferta alcanza los 21 puntos porcentuales, mientras que en el caso de los apartamentos turísticos es de 15 puntos porcentuales.

Los datos anteriores pueden complementarse con las ratios entre las pernoctaciones y las plazas ofertadas por los distintos alojamientos. En este caso, los establecimientos hoteleros y los apartamentos turísticos experimentaron un aumento de las pernoctaciones por plaza de 2,51 y 0,95 respectivamente, lo que constituye un indicador positivo para ambos tipos de alojamiento.

Tabla 1. Evolución de oferta y demanda turística en la Comunidad de Madrid

\begin{tabular}{|c|c|c|c|c|c|c|c|}
\hline & \multirow[b]{2}{*}{ Años } & \multicolumn{2}{|l|}{ Total } & \multicolumn{2}{|c|}{\begin{tabular}{|l}
$\begin{array}{l}\text { Alojamiento } \\
\text { Hotelero }\end{array}$ \\
\end{tabular}} & \multicolumn{2}{|c|}{ Apartamentos turísticos } \\
\hline & & Plazas & Pernoctaciones & Plazas & Pernoctaciones & Plazas & Pernoctaciones \\
\hline \multirow[b]{2}{*}{ Valores absolutos } & 2001 & 67.497 & 1.083 .488 & 62.750 & 1.015 .363 & 4.747 & 68.125 \\
\hline & 2019 & 125.161 & 2.303 .776 & 114.330 & 2.137 .969 & 10.831 & 165.807 \\
\hline Variación porcentual & & $46,07 \%$ & $52,97 \%$ & $82,20 \%$ & $103,35 \%$ & $128,17 \%$ & $143,38 \%$ \\
\hline \multirow{2}{*}{$\begin{array}{ll}\text { Ratio: } & \text { Pernoctaciones/ } \\
\text { Plazas } & \\
\end{array}$} & 2001 & \multicolumn{2}{|l|}{16,05} & \multicolumn{2}{|l|}{16,18} & \multicolumn{2}{|l|}{14,35} \\
\hline & 2019 & \multicolumn{2}{|l|}{18,41} & \multicolumn{2}{|l|}{18,69} & \multicolumn{2}{|l|}{15,30} \\
\hline Variación & & \multicolumn{2}{|c|}{2,35 puntos porcentuales } & \multicolumn{2}{|c|}{2,51 puntos porcentuales } & \multicolumn{2}{|c|}{0,95 puntos porcentuales } \\
\hline
\end{tabular}

Fuente: Elaboración propia a partir de datos del INE (EOAH, EOTR, EOAP)

Las plataformas P2P de alojamiento turístico, como Airbnb, surgen en nuestro país apoyadas por la transformación digital, y afectan a la estructura de la oferta y la demanda turística. En concreto, el crecimiento y consolidación de Airbnb como plataforma líder de alojamiento extrahotelero justifica su análisis en el ámbito del alojamiento turístico y el estudio de su impacto territorial. Además, se realiza una revisión del papel que deben desempeñar los gestores turísticos para que la economía pueda alcanzar el bienestar social. 
En este contexto, la presente investigación tiene como objetivo principal conocer el impacto territorial de Airbnb en la ciudad de Madrid para comprender la situación del destino, no solo desde el punto de vista del turista, sino desde el punto de vista del residente. Se investigará en qué medida, mediante un análisis cluster con datos obtenidos de Airbnb en la ciudad de Madrid, es posible identificar diferentes zonas según sus niveles de turistificación y detectar de forma temprana procesos de turistificación de los barrios garantizando la sostenibilidad de los destinos. Por consiguiente, con este artículo se tratará de dar respuesta a la siguiente pregunta de investigación: ¿Los datos de los alojamientos de Airbnb pueden servir como indicadores de alerta temprana para detectar zonas que sufren procesos de turistificación?

La novedad de este estudio es triple: (a) Por un lado, se trata de contribuir a la investigación de Airbnb, como plataforma líder de alojamiento P2P, estudiando la implementación de su impacto territorial como indicador de alerta temprana para localizar zonas que sufren procesos de turistificación. Los resultados ayudarán a comprender la utilidad gestora y social de estos datos como indicadores para los destinos. (b) En segundo lugar, el análisis de los datos de alquiler turístico en Airbnb se complementará con el análisis de los datos de alquiler residencial de Fotocasa, con el fin de detectar si estos últimos permiten detectar de forma temprana procesos de gentrificación de los barrios, esto es, cambios en su población con la entrada de nuevos residentes de estatus socioeconómico superior como consecuencia de una transformación en el espacio construido. (c) Por último, la investigación abre una discusión sobre las diversas estrategias de descentralización turísticas, tanto las implementadas por el propio Ayuntamiento de Madrid como otras estrategias implementadas por países europeos como es el caso de Ámsterdam mediante el uso de algoritmos.

En primer lugar, se realizará un estudio descriptivo y una primera agrupación de los distritos en función del número de apartamentos de Airbnb a 17/01/18 y 14/01/19. Para las mismas fechas, se realizará una segunda agrupación de los distritos en función del número de apartamentos de Airbnb por $\mathrm{km}^{2}$. Estas dos agrupaciones permitirán identificar zonas más sensibles en cuanto a la densidad de alojamientos y detectar posibles procesos de turistificación de ciertos distritos. Posteriormente, se realizará una tercera agrupación considerando el precio medio de los apartamentos de Airbnb para observar las zonas con mayor sensibilidad en cuanto al precio. Por último, con la finalidad de comprender la situación del destino, no solo desde el punto de vista del turista, sino desde el punto de vista del residente, y detectar posibles procesos de gentrificación en los barrios, se añade un análisis transversal del alquiler residencial, permanente, con datos de la empresa Fotocasa que, en este caso, se agrupan por distritos en función del precio del alquiler por $\mathrm{m}^{2}$ en enero de 2018 y enero de 2019. En función de los resultados de las agrupaciones anteriormente mencionadas, se propone el uso de los datos utilizados para la identificación de forma temprana de procesos de turistificación o gentrificación de las zonas de una ciudad, pudiendo ser una de las herramientas que garantice la sostenibilidad de los destinos.

La organización del trabajo de investigación es la siguiente: tras una breve introducción sobre la evolución de la demanda y la oferta turística de la capital española se realiza una revisión teórica de los procesos de turistificación en las ciudades, centrándose en el caso madrileño y la influencia de Airbnb en estos procesos. Seguidamente, se describe el caso de estudio y la metodología utilizada para alcanzar los objetivos planteados. Posteriormente, se exponen los resultados obtenidos del estudio y se finaliza con la presentación de las principales conclusiones derivadas del mismo. 


\section{MARCO TEÓRICO}

El marco teórico de la presente investigación revisa la literatura sobre los procesos de turístificación de las ciudades y Airbnb.

\subsection{Airbnb y los procesos de turistificación en las ciudades}

Comprender los procesos de turistificación de las ciudades es necesario para entender el fenómeno Airbnb y su impacto en los entornos urbanos. Dentro de las ciudades europeas, la actividad turística tiende a concentrarse en los centros urbanos, en general, espacios con notable valor histórico y patrimonial. Como consecuencia, estos espacios han estado sometidos a un intenso y prolongado proceso de turistificación (Calle, 2019), que conlleva una transformación funcional del espacio, con proliferación de las actividades vinculadas directa o indirectamente al consumo de los visitantes (Knafou, 1996). El alcance de esta transformación varía en función de la magnitud de la actividad turística, las características específicas de cada centro y la capacidad de los gobiernos locales para encarar esta situación (Calle, 2019).

Desde el punto de vista socioeconómico, se ha de tener en cuenta que la actividad turística puede ayudar a mejorar los territorios, pero también puede ser un vector de transformación negativa que amenace su propia condición urbana. Particularmente, durante los últimos años, se ha producido un crecimiento de la afluencia de turistas en los entornos urbanos y la aparición de una serie de fenómenos, de alcance todavía incierto, como el uso turístico del parque de viviendas. Como consecuencia de estas transformaciones, el debate sobre la turistificación de las ciudades y sus efectos ha tenido un gran impacto en los círculos académicos y en los medios de comunicación, con la utilización de términos como turistificación, saturación turística u "overtourism".

El concepto de turistificación hace referencia al impacto que tiene la masificación turística en el tejido comercial y social de determinados barrios o ciudades (Fendéu BBVA, 2017). Un impacto que, según la literatura más reciente, parece haber provocado distintos resultados en los barrios y ciudades (Vestri, 2020), como: (1) el aumento de la tensión en el mercado inmobiliario, revirtiendo en un creciente desplazamiento espacial de la población (Pixová y Sládek, 2016), (2) un proceso de desposesión de los vecinos estimulado por la rápida turistificación de sus barrios (Janoschka y Sequera, 2016), (3) la marginalización progresiva de prácticas no deseadas mediante políticas gubernamentales de tolerancia-cero (Cummings, 2015), (4) la promoción de nuevas formas de ocio hedonista, mercantilizado y juvenil en horario nocturno, que revierten en tensiones vecinales (Nofre et al., 2018), (5) la desaparición paulatina de la venta al por menor reemplazada por negocios meramente turísticos (González y Waley, 2013) y, finalmente, (6) la relación entre el concepto turistificación urbana (Ashworth y Stephen, 2011) y la propia crisis de la vivienda (Lee, 2016).

Todos los motivos anteriormente mencionados han producido que el debate sobre la turistificación se haya disparado en los últimos años y, en muchos casos, se haya superpuesto al de la gentrificación. El proceso de gentrificación implica un cambio en la población de usuarios de un respectivo territorio, implicando que los nuevos usuarios sean de un estatus socioeconómico superior al de los anteriores, acompañado de una transformación en el espacio construido mediante la reinversión de capital fijo (Clark, 2005, p. 258 citado por Sorando y Ardura, 2016, p. 21). Así, la gentrificación es el proceso de reocupación de un área 
urbana por una determinada clase socioeconómica en detrimento de otra. Generalmente, el área en cuestión ha sufrido un proceso de abandono y deterioro y la llegada de esa nueva clase social, con un nivel adquisitivo mayor y nuevas necesidades, provoca una serie de cambios (reconversión urbana, mejoras materiales, mejoras en la oferta recreativa, equipamientos, cambios culturales y sociales, etc.) que se traducen en una revalorización del suelo y en un mayor coste de vida para sus residentes.

Los movimientos urbanos provocados por la turistificación difieren de los provocados por la gentrificación, en que ya no son los nuevos residentes los que desplazan a los antiguos porque tienen un mayor nivel adquisitivo, sino los turistas que vienen por cortos periodos de tiempo. El resultado es el mismo en los dos casos, esto es, el desplazamiento de las personas residentes, pero las transformaciones en el barrio no son iguales, ya que se producen nuevos cambios en el paisaje urbano que no responden únicamente a necesidades de consumo propias de las dinámicas gentrificadoras, sino a las necesidades turísticas.

Diversos autores consideran que la turistificación es impulsada por plataformas P2P como Airbnb, que contribuyen a crear conflictos en los barrios de las ciudades (Santos y Sequera, 2018) y han abierto el debate sobre un nuevo concepto de gentrificación como 'gentrificación 4.0', que podría definirse por el vaciamiento poblacional, es decir, por el desplazamiento de la población original por una 'no-población' (Porras y García Castaño, 2016). Tras la aparición de Airbnb y su exponencial crecimiento, se comenzó a cuestionar si la definición de economía colaborativa encajaba con la concepción de Airbnb y si dicha empresa estaba muy alejada de dirigir la economía hacia la sostenibilidad. Así, algunas administraciones públicas españolas han limitado, e incluso impedido, el desarrollo de estas economías, si bien lo han hecho de manera fragmentada y descoordinada debido a la posibilidad de legislar de forma independiente, ya que las Comunidades Autónomas tienen transferida la gestión en el ámbito turístico (Rodríguez-Antón et al., 2016).

Cuando se realiza una revisión de las investigaciones y estudios sobre Airbnb se evidencia que existen múltiples investigaciones que versan sobre el impacto de Airbnb en diferentes aspectos de la economía y la sociedad. La mayoría de estos estudios analizan el impacto sobre el consumidor (19/50), tal como se observa en la Tabla 2. Por otra parte, las investigaciones que estudian el impacto territorial de Airbnb ocupan una posición de notoriedad dentro de los artículos más citados de Web of Science, pero no son el área temática más investigada, ya que tan solo 7 de los 50 artículos más citados de WoS sobre Airbnb, versan sobre el impacto territorial. Por todo ello, se considera que los estudios que versan sobre este tipo de efecto, como ocurre con el presente trabajo, pueden aportar interesantes contribuciones científicas.

Si se examinan las distintas investigaciones que analizan el impacto territorial de Airbnb en distintas ciudades, se perciben diferentes líneas de investigación al respecto (Ver Tablas 2 y 3 ):

- Efecto territorial y su visualización en el territorio: algunas de las investigaciones más citadas por Web of Science sobre Airbnb y su impacto, analizan el efecto territorial de Airbnb. En varias de estas investigaciones la metodología más usada son los estudios de caso acompañados de mapas de densidad (Gant 2016; Gurran y Phibbs, 2017; Horn y Merante, 2017; Wegmann y Jiao, 2017; Yrigoy, 2017). Gracias al uso de técnicas basadas en mapas, muchas de las investigaciones posibilitan la visualización del 
impacto de Airbnb en el territorio (Dudás et al, 2017; Gant, 2016; Gurran y Phibbs, 2017; Horn y Merante, 2017; Nofre et al., 2018; Wegmann y Jiao, 2017; Yrigoy, 2017).

- Impacto en el mercado inmobiliario: varios de los estudios se centran en el análisis del impacto de Airbnb sobre el mercado del alquiler (Dudás et al., 2017; Gant, 2016; Horn y Merante, 2017; Yrigoy, 2017) y el mercado inmobiliario (Dudás et al, 2017; Gurran y Phibbs, 2017; Horn y Merante, 2017; Wegmann y Jiao, 2017).

Tabla 2. Resultados de la revisión sistemática

\begin{tabular}{|c|c|}
\hline $\mathbf{5 0}$ artículos más citados de Web Of Science con Tema = (Airbnb * AND (impacto OR efecto OR \\
repercusión ...)
\end{tabular}

Elaboración propia

Tabla 3. Análisis de los 7 artículos más citados que analizan el impacto territorial de Airbnb

\begin{tabular}{|c|c|c|c|}
\hline Autores & Método usado & $\begin{array}{l}\text { Tipo de } \\
\text { impacto }\end{array}$ & Área específica de impacto \\
\hline $\begin{array}{l}\text { Gurran, Nicole; } \\
\text { Phibbs, Peter }\end{array}$ & $\begin{array}{l}\text { Estudio de caso con } \\
\text { mapas de densidad }\end{array}$ & Territorial & $\begin{array}{l}\text { Impacto económico general e impactos de } \\
\text { Airbnb en Sydney (territoriales y regulación) }\end{array}$ \\
\hline $\begin{array}{l}\text { Cocola-Gant, } \\
\text { Agustin }\end{array}$ & $\begin{array}{l}\text { Estudio de caso con } \\
\text { mapas de densidad } \\
\text { y estudio cualitativo }\end{array}$ & Territorial & $\begin{array}{l}\text { Los impactos de los alquileres vacacionales } \\
\text { en el centro histórico de Barcelona }\end{array}$ \\
\hline $\begin{array}{l}\text { Horn, Keren; } \\
\text { Merante, Mark }\end{array}$ & $\begin{array}{l}\text { Estudio de caso con } \\
\text { mapas de densidad }\end{array}$ & Territorial & $\begin{array}{l}\text { Impacto sobre el mercado inmobiliario y el } \\
\text { mercado de alquiler en Boston }\end{array}$ \\
\hline $\begin{array}{l}\text { Wegmann, Jake; } \\
\text { Jiao, Junfeng }\end{array}$ & $\begin{array}{l}\text { Webscraping y } \\
\text { mapas de densidad }\end{array}$ & Territorial & $\begin{array}{c}\text { Impacto de Airbnb en el impacto inmobiliario } \\
\text { en Austin, Boston, Chicago, San Francisco y } \\
\text { Washington, DC. }\end{array}$ \\
\hline $\begin{array}{c}\text { Nofre, Jordi; } \\
\text { Giordano, } \\
\text { Emanuele; Eldridge, } \\
\text { Adam; Martins, Joao } \\
\text { C.; Sequera, Jorge }\end{array}$ & $\begin{array}{c}\text { Revisión crítica } \\
\text { diacrónica y trabajo } \\
\text { de campo } \\
\text { etnográfico }\end{array}$ & Territorial & $\begin{array}{l}\text { La planificación urbana desarrollada en la } \\
\text { Barceloneta durante el período 1950-2016 } \\
\text { en la transformación del barrio }\end{array}$ \\
\hline Yrigoy, Ismael & $\begin{array}{l}\text { Estudio de caso con } \\
\text { mapas de densidad }\end{array}$ & Territorial & $\begin{array}{l}\text { El impacto de los alquileres turísticos en el } \\
\text { mercado de alquiler residencial en Menorca }\end{array}$ \\
\hline $\begin{array}{l}\text { Dudás, Gabor; } \\
\text { Boros, Lajos; } \\
\text { Kovalcsik, Tamas; } \\
\text { Kovalcsik, Balazs }\end{array}$ & $\begin{array}{l}\text { Método de minería } \\
\text { de datos (mapas } \\
\text { ráster de } 3 \text { bandas) }\end{array}$ & Territorial & $\begin{array}{l}\text { Análisis del patrón espacial intraurbano de } \\
\text { Airbnb en Hungría }\end{array}$ \\
\hline
\end{tabular}

Elaboración propia

\subsection{El caso de Madrid}

El caso de la ciudad de Madrid es un caso singular en el proceso de turístificación urbana. Si se analiza el caso del distrito Centro, se puede constatar que el centro de la ciudad ha sufrido importantes transformaciones durante los últimos 40 años, mostrando una 
gentrificación clásica o similar a la de otras ciudades de Europa (Leal, 2004). Sin embargo, Madrid se ha convertido en un referente de los procesos de turistificación transnacional por su condición semi periférica, donde, como Lisboa (Sequera y Nofre, 2019) y Barcelona (CocolaGant y Lopez-Gay, 2020), el mercado inmobiliario ha pasado de tener un enfoque largoplacista a un tener un enfoque orientado al uso turístico a corto plazo. En una investigación sobre la oferta de alquiler vacacional en Madrid durante los años 2015-2018, se verifica una fuerte asociación entre el crecimiento de la llegada de turistas, el asentamiento de nuevos residentes con mayor poder adquisitivo y los precios de alquiler crecientes (Ardura et al., 2020).

Todos los movimientos urbanos anteriormente mencionados han provocado que gran cantidad de viviendas hayan sido derivadas al alquiler turístico de corta estancia mediante plataformas como Airbnb, con un impacto enorme en la ciudad. Además, Madrid es una de las ciudades del mundo donde el número de multipropietarios en Airbnb es mayor y el porcentaje de ofertas peer to peer menor, si lo comparamos con ciudades como Copenhague, Berlín, Ámsterdam, Nueva York, Sídney o San Francisco. Airbnb en Madrid se caracteriza por tener muy pocos actores que controlan la mayoría del mercado y cuanto mayor es el peso del modelo comercial de Airbnb en una ciudad, mayor es su impacto sobre los procesos de turistificación (Santos y Sequera, 2018). Ante estos fenómenos, la presente investigación pretende analizar el caso de la plataforma Airbnb, como una de las principales plataformas de alquiler turístico de corta estancia y líder entre las plataformas de alojamiento peer-to-peer (Lalicic y Weismayer, 2017), ya que los datos de ingresos anuales de la misma se cifraban, ya en 2015, en más de 25 mil millones de dólares al año con más de 6 millones de usuarios (Kokalitcheva, 2015). A nivel general, los análisis realizados por diferentes investigadores sobre la plataforma Airbnb en Madrid muestran que la mayoría de las ofertas de alquiler turístico en la ciudad presentan pisos completos, frente a modalidades de pisos y habitaciones compartidas. Otro dato destacable, en el caso madrileño, es que más de la mitad de las ofertas pertenecen a multipropietarios (Ardura, 2017; Ayuntamiento de Madrid, 2017; Gil, 2018).

\section{METODOLOGÍA}

Para la realización de la investigación se han utilizado fuentes secundarias con la finalidad de conocer la composición por distritos de la ciudad de Madrid y, posteriormente, se ha utilizado la metodología clúster para conocer y clasificar el impacto territorial de Airbnb en la capital de España.

Tras la presentación de los antecedentes teóricos de este trabajo de investigación se realiza, en primer lugar, un análisis del caso Airbnb en Madrid, presentándose la composición del territorio madrileño por distritos. Se muestra, además, la situación actual que está experimentando la oferta alojativa de Airbnb en Madrid. Posteriormente, se realiza una clasificación de los distintos distritos madrileños en función de diferentes variables relacionadas con el tamaño del distrito y la oferta de Airbnb, así como la oferta de alquileres de Fotocasa.

El propósito del análisis anteriormente mencionado es realizar distintas agrupaciones de los distritos madrileños en función de diferentes variables que funcionarán como indicadores para determinar el grado de impacto de Airbnb en los distintos distritos, logrando, así, una mejor comprensión del impacto territorial que tiene Airbnb en la capital española. Además, se incluye una instantánea desde el punto de vista de los alquileres permanentes 
mediante Fotocasa, lo cual enriquece el análisis del territorio, ya que incorpora una visión más completa del paradigma, no solo turístico, sino residencial.

Para realizar las diferentes agrupaciones se hace uso de la técnica de análisis clúster, consiguiendo 4 agrupaciones distintas mediante diferentes variables.

La primera agrupación se realiza mediante las siguientes variables:

a) Número de apartamentos completos de Airbnb a 17/01/2018

b) Número de apartamentos completos de Airbnb a 14/01/2019

Esta agrupación permite conocer la distribución de los apartamentos por distritos en dos periodos diferentes con el fin de observar las zonas con mayor densidad de alojamientos.

La segunda agrupación permite relativizar la congregación anterior en función de la dimensión del territorio, pues las variables de la primera agrupación se relativizan en función de los $\mathrm{km}^{2}$ de los distritos:

c) Número de apartamentos completos de Airbnb/ $\mathrm{km}^{2}$ a 17/01/2018

d) Número de apartamentos completos de Airbnb/ $\mathrm{km}^{2}$ a 14/01/2019

Estas dos primeras agrupaciones se presentan junto con sus estadísticos y los grupos resultantes se representan mediante mapas. Así, se consigue conocer qué distritos ofrecen una mayor cantidad de alojamientos turísticos a través de Airbnb, así como su distribución, incorporando una matización en la segunda agrupación que permite analizar esta distribución en función de la propia capacidad del territorio.

Para complementar la situación de la oferta turística de Airbnb, se hace una tercera agrupación en función del precio medio de los alojamientos completos de Airbnb. Esta acción permite observar si las zonas con mayor densidad de plazas turísticas experimentan precios más elevados:

e) Precio medio de los apartamentos completos de Airbnb del 17/01/18

f) Precio medio de los apartamentos completos de Airbnb del 14/01/19

Tras analizar detenidamente las agrupaciones resultantes y sus características, se incorpora una cuarta agrupación, que permite enriquecer el análisis, desde una perspectiva residencial del destino. Se incorpora una agrupación mediante el precio de los alquileres permanentes de Fotocasa, a fin de detectar si las zonas más sensibles al precio en el alquiler turístico se corresponden con las del alquiler permanente:

a) Precio del alquiler/m2 de los apartamentos de Fotocasa en enero 2018

b) Precio del alquiler/m2 de los apartamentos de Fotocasa en enero 2019

El análisis clúster es una técnica de análisis multivariante que se emplea para establecer diferentes grupos de individuos sobre la base de características comunes (Aldenderfer y Blashfield, 1984; Bailey, 1994; Ketchen y Shook, 1996). Considerando que los resultados de un análisis clúster podrían diferir en función del método aplicado, se ha optado por llevar a cabo dos de tipo jerárquico (considerando el método de Ward y el método complete linkage con las distancias euclídeas) y otro de tipo iterativo (método de K-medias), con el fin de cerciorarse la robustez de los resultados. Para la presente investigación se optó 
por el clúster jerárquico con el método de Ward, pues uno de los más utilizados en la práctica, teniendo la mayoría de ventajas del método de la media y siendo más discriminativo en la determinación de los niveles de agrupación.

\section{RESULTADOS}

4.1. El impacto de Airbnb en Madrid: número de apartamentos, densidad de plazas turísticas por kilómetro cuadrado y precios (distribución por distritos)

La ciudad de Madrid se encuentra distribuida en 21 distritos territoriales, tal como recoge la figura 1. Dicha distribución geográfica de la ciudad en distritos es completamente dispar, es decir los distritos tienen dimensiones muy distintas entre si, hecho que se ha de considerar para comprender mejor el panorama en el que se encuentran inmersos los diferentes distritos.

Figura 1. Distribución de los distritos madrileños

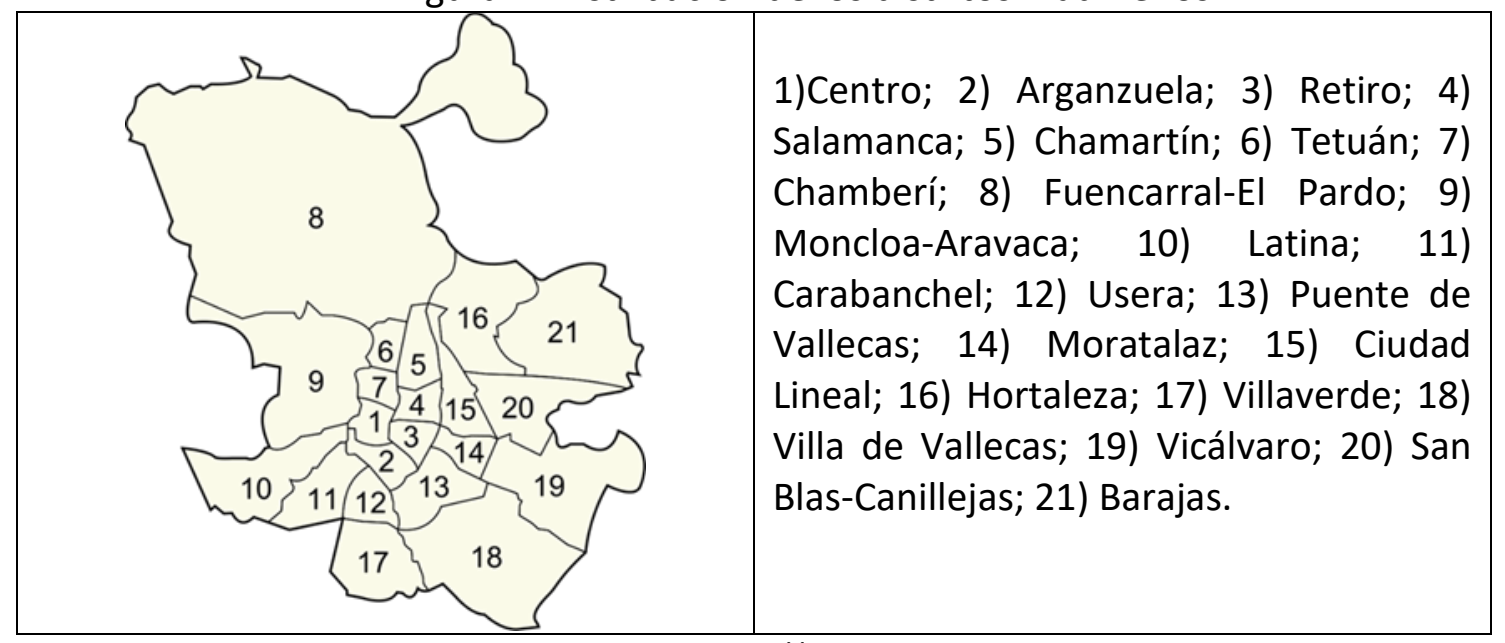

Fuente: https://www.madrid.es

La ciudad cuenta con 21 distritos, repletos de monumentos, parques y otros muchos atractivos, en muchos casos desconocidos por viajeros y visitantes de la ciudad. Por ello en 2017 el Ayuntamiento, a través de Madrid Destino, lanzó una campaña para informar a ciudadanos y visitantes sobre espacios de interés turístico en los barrios de la capital (Véase Figura 2). 
Figura 2. Imagen Madrid Destino

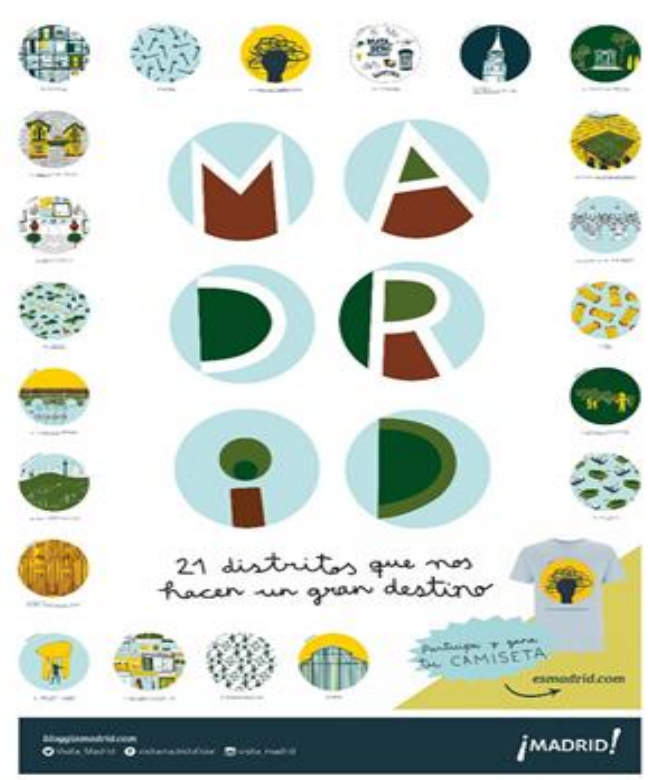

Fuente: https://diario.madrid.es/blog/notas-de-prensa/madrid-21-distritos-que-nos-hacen-un-gran-destino/

Esta iniciativa pretendía dar a conocer una amplia visión de la ciudad, más allá del Centro y de sus espacios emblemáticos. El objetivo era hacer de Madrid una ciudad turísticamente sostenible, distribuyendo el flujo de viajeros y los beneficios del turismo al conjunto de los distritos de la capital.

Con el lema Madrid, 21 distritos que nos hacen un gran destino, se informaba a la ciudadanía y a los visitantes sobre otros espacios de interés turístico de la capital, con el objetivo de hacer de Madrid una ciudad sostenible turísticamente, con un equilibrio entre el día a día de la ciudad y sus ciudadanos y el flujo de viajeros.

Según el Ayuntamiento de Madrid, dotando de información a los visitantes sobre otros recursos de interés para ser visitados fuera del centro de la ciudad, se perseguía evitar la concentración de la almendra turística, distribuir los ingresos por turismo a todos los distritos de Madrid, elevar las visitas en periodos de baja ocupación de la ciudad, así como favorecer la creación de empleo vinculado al sector turístico madrileño (Diario de Madrid, 2017). El proyecto, desde 2019, ha pasado a ser un proyecto cultural multidisciplinar de la Concejalía de Cultura del Ayuntamiento de Madrid, con impacto en todos los distritos (https://21distritos.es/), más dirigido a los madrileños que al visitante de la ciudad.

En esa composición de 21 distritos, la ciudad tiene registrados en enero de 2018, 10.338 apartamentos completos en Airbnb, que crecen a 11.353 en enero de 2019. La distribución de los apartamentos por distritos es ampliamente dispar (ver Figura 3) y es el distrito Centro el que acoge al $60 \%$ de los apartamentos que la plataforma oferta en Madrid (capital o provincia). Si se observa en el mapa de la figura 2, la zona Centro, es una parte ínfima de la provincia madrileña en su conjunto, sin embargo, dicho distrito ampara a más de la mitad de los apartamentos en un espacio geográfico muy limitado. Estos datos, son indicativos de la realidad que está experimentando la ciudad, realidad, que ha sido denominada como turistificación de las zonas céntricas. Este concepto se entiende como un proceso de construcción de un lugar como un destino turístico (Navarro y Vejsberg, 2009), basado en la relación entre patrimonio, prácticas y turismo. 
Si se sigue analizando el resto de distritos, tras el distrito Centro, seguirían con un 7\%, $5 \%, 5 \%$ y $4 \%$ los distritos de Salamanca, Chamberí y Arganzuela y Tetuán respectivamente. Tras estos, encontramos dos distritos con un 3\% de los apartamentos cada uno: Retiro, y Chamartín. Los restantes distritos contienen un $2 \%$ o menos de los apartamentos ofertados por Airbnb en Madrid.

Figura 3. Distribución de los apartamentos completos de Airbnb por distritos

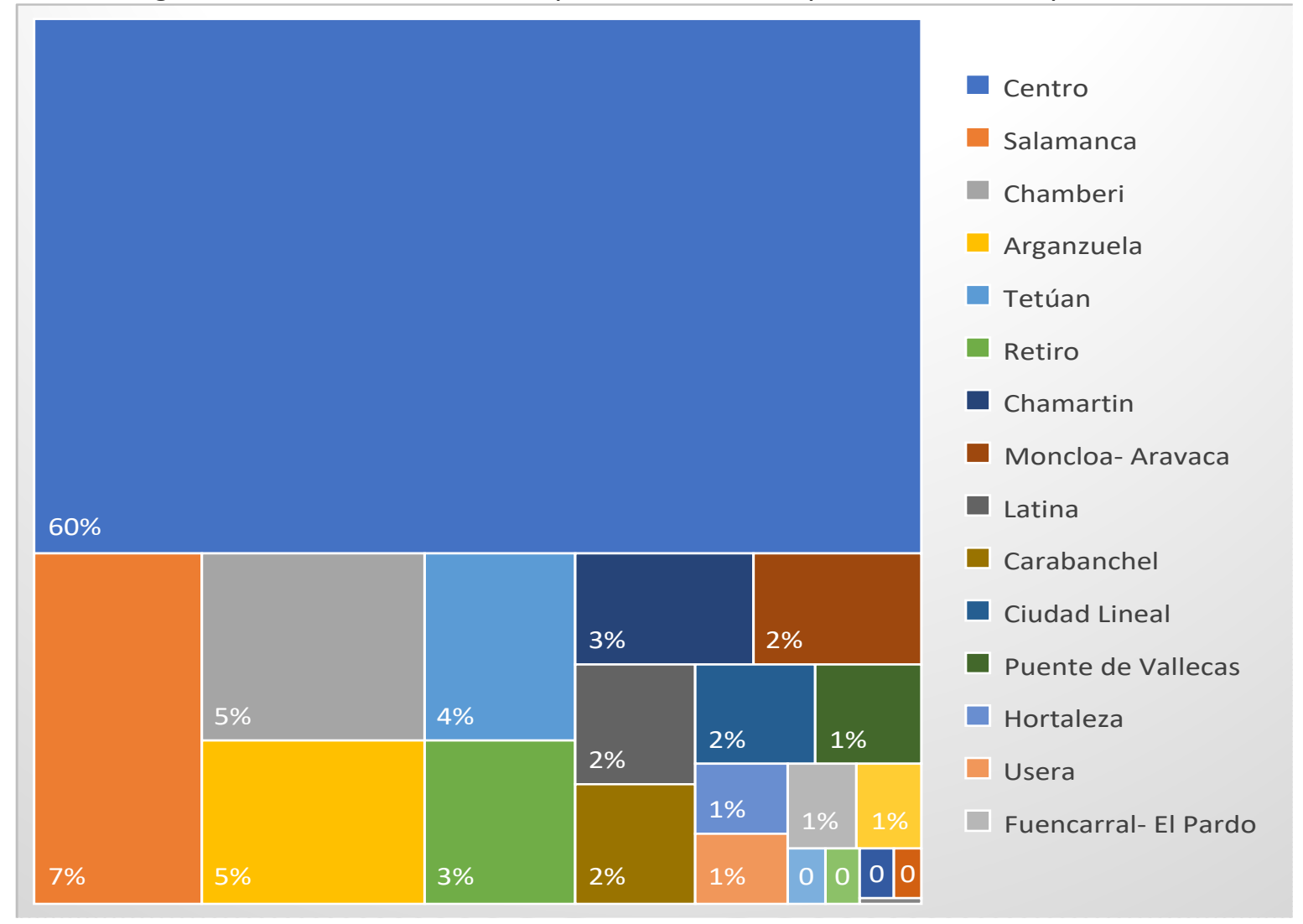

Fuente: Elaboración propia mediante los datos de Tom Slee del 2019

Al analizar la densidad de plazas turísticas de Madrid comercializadas en Airbnb por kilómetro cuadrado (ver Figura 4), se detecta que las viviendas turísticas ofertadas en Airbnb se concentran en el distrito Centro (con una densidad aproximada de 1.306 plazas turísticas de Airbnb/ $\mathrm{km}^{2}$ ).

A una distancia más que considerable del distrito Centro en términos de densidad, se encuentran el distrito de Salamanca y el distrito de Chamberí (que poseen una densidad aproximada de 156 y 130 plazas turísticas de Airbnb/ $\mathrm{km}^{2}$ ). Tras estos, con una diferencia bastante notable en cuanto a la densidad de plazas turísticas por $\mathrm{km}^{2}$, se encuentran los distritos de Arganzuela, Tetuán y Retiro (estos tienen una densidad de 80, 77 y 67 plazas turísticas de Airbnb / $\mathrm{km}^{2}$, respectivamente). Posteriormente, encontramos los distritos de Chamartín, Ciudad Lineal, Carabanchel y Usera (con una densidad entre 31, 15, 15 y 12 plazas turísticas de Airbnb / $\mathrm{km}^{2}$ respectivamente).

Finalmente, el resto de los distritos: Puente de Vallecas, La Latina, Moncloa-Aravaca, San Blas- Canillejas, Hortaleza, Moratalaz, Villaverde, Barajas, Villa de Vallecas, Fuencarral- El Pardo y Vicálvaro (con una densidad de menos de 10 plazas turísticas de Airbnb $/ \mathrm{km}^{2}$ ). De 
estos últimos, cabe destacar el caso de Moncloa-Aravaca, ya que es un distrito con mucha demanda residencial, pero que posee una oferta reducida en Airbnb en función de sus $\mathrm{km}^{2}$.

Al analizar la disparidad entre distritos, se observa qué tanto las cifras absolutas como las relativas, nos indican una elevada concentración de apartamentos en el distrito Centro. Por otra parte, ha de considerarse que algunos autores plantean que, el mercado de Airbnb en la ciudad de Madrid está en gran parte controlado por actores profesionales que no cumplen los principios de la economía colaborativa y cuya actividad se basa en aprovechar los rent gaps que genera Airbnb y ampliar las rentas inmobiliarias por medio de sustituir vivienda residencial en vivienda turística, lo que impulsa los procesos de turistificación (Gil y Sequera, 2018; Sequera y Nofre, 2018).

Figura 4. Densidad de plazas turísticas de Madrid comercializadas en Airbnb por $\mathrm{km}^{2}$ (2018)

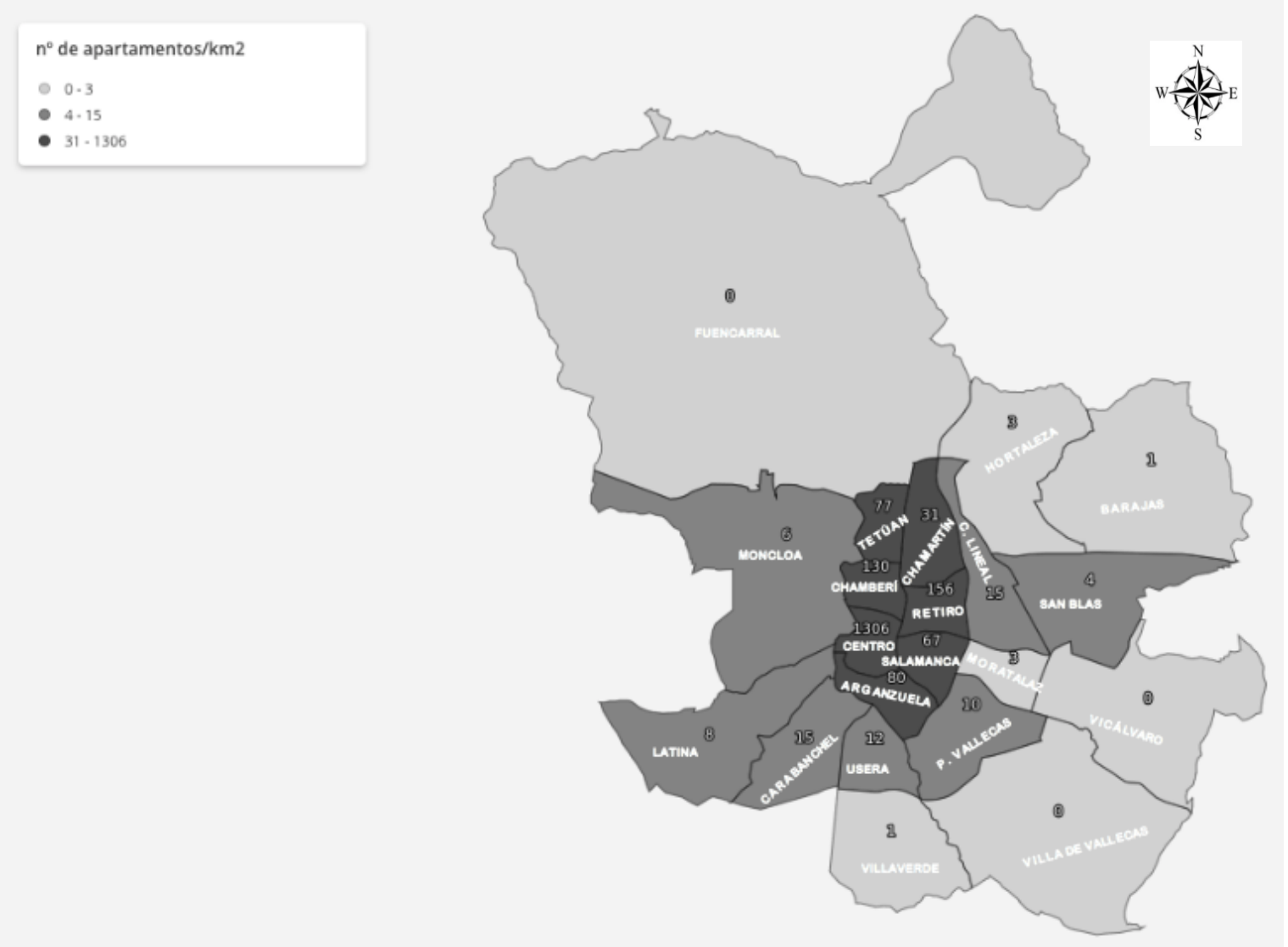

Fuente: Elaboración propia con Carto mediante los datos de Airbnb 2019

En cuanto a la distribución por distritos referenciando el precio medio por noche de apartamento completo (ver Figura 5), debe considerarse la siguiente evidencia: los distritos con mayor número de apartamentos no se corresponden necesariamente con los distritos con mayor precio medio por apartamento. Es más, si se establece en el gráfico una línea para determinar qué distritos se quedan por debajo de la media por apartamento de la ciudad madrileña en 2018 (84 euros) y qué distritos están por encima, se observa que el distrito Centro queda por encima (93 euros), aunque muy próximo a la media de la ciudad.

Los distritos que son iguales o superiores a la media en cuanto a precio medio por apartamento completo de Airbnb en el año 2018 son: Barajas, Villaverde, Centro, Arganzuela, Chamberí, Hortaleza, Moncloa-Aravaca, Chamartín, Retiro y Salamanca, en orden ascendente. Sin embargo, en el año 2019, el precio medio asciende hasta 110 euros y, además, la 
configuración de distritos iguales o superiores a la media es bastante distinta: Chamberí, Centro, Retiro, Moncloa- Aravaca, Salamanca, Tetuán, La Latina y Usera, en orden ascendente. El caso de los distritos de Usera y Latina es bastante peculiar, pero esa subida de precios viene motivada, principalmente, porque algunos alojamientos de lujo se ofertaban a precios muy elevados.

Todos los datos anteriormente expuestos, muestran que, si se analiza el precio medio por apartamento en los distritos, no necesariamente tiene que haber coincidencia entre las áreas con más oferta y demanda de apartamentos y las zonas con un mayor precio medio por apartamento. Precisamente, por este último motivo, es necesario contar con diversos indicadores que puedan detectar anomalías o saturaciones en el mercado del alquiler de los distintos distritos, para poder garantizar la sostenibilidad de estos.

Figura 5. Distribución por distritos del precio medio por noche del apartamento completo

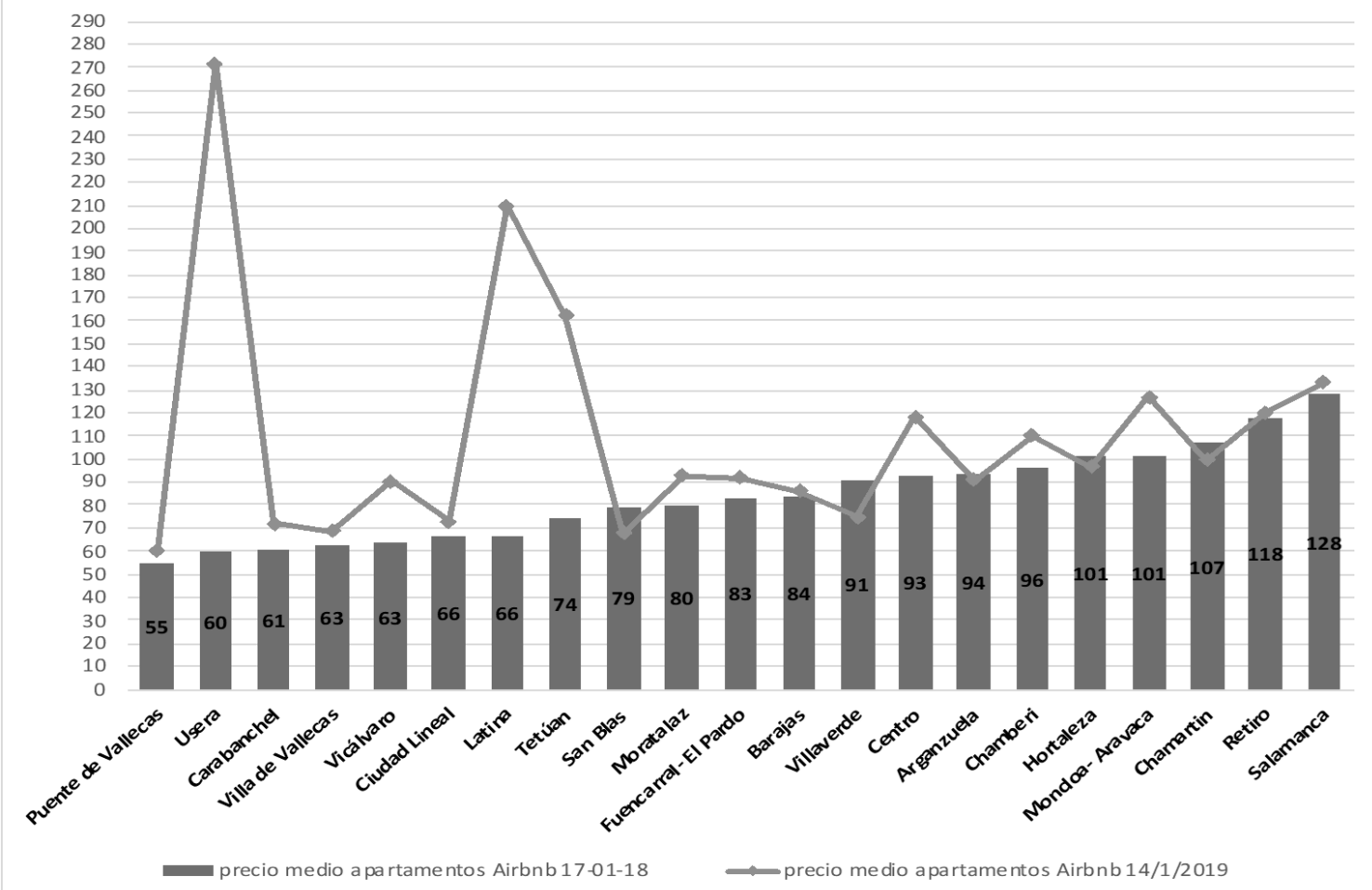

Fuente: Elaboración propia a partir de datos de Airbnb 2018 y 2019.

\subsection{Análisis descriptivo de los grupos de distritos}

En el análisis descriptivo se trabaja con los 21 distritos madrileños, con la finalidad de poder realizar distintas agrupaciones de los distritos en función de diversas variables, con el objetivo de conseguir una imagen más fidedigna de la situación de los alquileres turísticos en Madrid, e incluso de la posible repercusión en la situación de los alquileres permanentes. Se presentan los 21 distritos en la Tabla 4, lo que permite observar la configuración de las distintas agrupaciones en sus clústeres resultantes:

- El Clúster 1 está formado por los distritos que se han visto menos afectados por Airbnb y por el mercado de alquiler, por lo que, en este clúster, las variables son más bajas en media. Este grupo está compuesto por 17 distritos (en el caso de las agrupaciones 
relacionadas con el no de apartamentos de Airbnb o el precio medio de dichos apartamentos), 15 distritos (resultantes en la agrupación en función del número de apartamentos por $\mathrm{km}^{2}$ de Airbnb) y 10 distritos (en función del precio del alquiler permanente en Fotocasa).

- El Clúster 2 está compuesto por los distritos cuyas variables son bastante elevadas en media y se compone de 5 distritos, 3 distritos y 3 distritos, respectivamente.

- El Clúster 3 está integrado por aquellos distritos en los que Airbnb y el mercado de alquiler tienen un impacto exacerbado; en este caso, tres de las agrupaciones ( $n$ o de apartamentos de Airbnb, $\mathrm{n}$ - de apartamentos $/ \mathrm{km}^{2}$ de Airbnb y precio medio de los apartamentos de Airbnb) se dirigen a un único distrito: el Centro. Por su parte, la agrupación del alquiler permanente de Fotocasa recoge diversos distritos, además del Centro: Arganzuela, Chamartín, Chamberí, Moncloa-Aravaca, Retiro, Salamanca y Tetúan.

Una vez obtenidas estas agrupaciones de los distritos, se han calculado algunos estadísticos descriptivos, que vienen recogidos en la tabla 5 y que contribuyen a caracterizar a los distritos con mayor precisión. En primer lugar, se presenta la agrupación en función del número de apartamentos completos de Airbnb por distritos. Para esta agrupación se hace uso de esta variable en dos momentos de tiempo 2018 y 2019 y se observa una amplia distancia entre los tres clústeres, ya que el primero de ellos oscila en una media en torno a cien apartamentos, el segundo en torno a los seiscientos y el último excede de los mil apartamentos, por lo que se evidencia la notable distancia entre los grupos. Estos datos ha de matizarse ya que, debido a la amplia variedad de distritos que acoge el Clúster 1 (17 distritos), este clúster tiene una dispersión bastante elevada en las dos variables (en torno a un 0,85 ).

En la segunda agrupación, se encuentra el número de apartamentos completos de Airbnb por $\mathrm{km}^{2}$. Para esta agrupación se hace uso de la variable en dos momentos de tiempo 2018 y 2019, lo que permite analizar los datos en función de la dimensión de los distritos. En este caso, la distancia entre clústeres se hace aún más evidente, mostrando que el primero de ellos oscila la cantidad de 6 apartamentos por $\mathrm{km}^{2}$, mientras que los distritos del clúster 2 rondan los 90 apartamentos por $\mathrm{km}^{2}$ y por último el distrito Centro correspondiente al Clúster 3 supera los 1200 apartamentos por $\mathrm{km}^{2}$. Se reitera, de nuevo, la elevada variedad de distritos que acoge el Clúster 1 (17 distritos) por lo que sus variables también presentan una dispersión elevada, que ronda el 1,20.

En la tercera agrupación, se presenta el precio medio de los apartamentos completos de Airbnb, haciendo uso de los precios en dos periodos temporales distintos (2018 y 2019), lo que permite analizar la sensibilidad en los precios. En esta agrupación la distancia entre clústeres se hace más perceptible en 2018 frente a 2019, a pesar de esta matización, los precios se presentan en orden ascendente del clúster con menor número de alojamientos en media (Clúster 1) hasta el clúster con mayor número de alojamientos en media (Clúster 3 ). En este caso ha de tenerse en cuenta que los precios en 2019 se presentan muy elevados para los tres grupos de distritos, superando los 100 euros de media.

En la última agrupación, se presenta, además, una agrupación complementaria al alquiler turístico, como es una agrupación en función del precio del alquiler permanente. En este caso la agrupación se realiza mediante los datos dispuestos en la plataforma de Fotocasa sobre el precio de los alojamientos/m2 en dos periodos temporales sucesivos 2018 y 2019. Aunque la distancia entre clústeres no es muy elevada, se muestra evidente, lo que permite 
caracterizar a los grupos en los dos periodos, respetando un orden ascendente del precio del clúster 1 hasta el clúster 3. Por otra parte, se observa que, en 2019 el clúster 3 presenta una elevada dispersión $(0,78)$, motivada por tres distritos del grupo, que presentan unos precios más elevados en 2019 (rondando los 18 euros/m2) respecto al resto del grupo (que ronda los 15 euros/m2). Estos distritos son: Centro, Chamberí y Salamanca.

Tabla 4. Formación de los clústeres

\begin{tabular}{|c|c|c|c|c|c|c|c|c|c|}
\hline \multicolumn{4}{|c|}{$\begin{array}{l}\text { 1. № de Apartamentos de Airbnb } \\
\text { 3. Precio medio apartamentos Airbnb }\end{array}$} & \multicolumn{3}{|c|}{$\begin{array}{l}\text { 2. № de Apartamentos } \\
\text { de Airbnb/ } \mathrm{km}^{2}\end{array}$} & \multicolumn{3}{|c|}{$\begin{array}{l}\text { 4. Precio del alquiler } / \mathrm{m} 2 \\
\text { Fotocasa }\end{array}$} \\
\hline & Fr. & $\%$ & Distritos & Fr. & $\%$ & Distritos & Fr. & $\%$ & Distritos \\
\hline $\begin{array}{l}\text { Clúster 1- } \\
\text { Distritos } \\
\text { con bajo } \\
\text { impacto }\end{array}$ & 17 & 80,95 & $\begin{array}{c}\text { Barajas } \\
\text { Chamartín } \\
\text { Carabanchel } \\
\text { Ciudad Lineal } \\
\text { Fuencarral- El Pardo } \\
\text { Hortaleza } \\
\text { Latina } \\
\text { Moncloa- Aravaca } \\
\text { Moratalaz } \\
\text { Puente de Vallecas } \\
\text { Retiro } \\
\text { San Blas } \\
\text { Tetuán } \\
\text { Usera } \\
\text { Vicálvaro } \\
\text { Villa de Vallecas } \\
\text { Villaverde }\end{array}$ & 15 & 71,43 & $\begin{array}{c}\text { Barajas } \\
\text { Chamartín } \\
\text { Carabanchel } \\
\text { Ciudad Lineal } \\
\text { Fuencarral- El Pardo } \\
\text { Hortaleza } \\
\text { Latina } \\
\text { Moncloa- Aravaca } \\
\text { Moratalaz } \\
\text { Puente de Vallecas } \\
\text { San Blas } \\
\text { Usera } \\
\text { Vicálvaro } \\
\text { Villa de Vallecas } \\
\text { Villaverde }\end{array}$ & 10 & 47,62 & $\begin{array}{c}\text { Barajas } \\
\text { Carabanchel } \\
\\
\text { Latina } \\
\text { Moratalaz } \\
\text { Puente de Vallecas } \\
\text { San Blas } \\
\text { Usera } \\
\text { Vicálvaro } \\
\text { Villa de Vallecas } \\
\text { Villaverde }\end{array}$ \\
\hline $\begin{array}{c}\text { Clúster 2- } \\
\text { Distritos } \\
\text { con } \\
\text { impacto } \\
\text { elevado }\end{array}$ & 5 & 14,29 & $\begin{array}{l}\text { Arganzuela } \\
\text { Chamberí } \\
\text { Salamanca }\end{array}$ & 3 & 23,91 & $\begin{array}{l}\text { Arganzuela } \\
\text { Chamberí } \\
\text { Retiro } \\
\text { Salamanca } \\
\text { Tetuán }\end{array}$ & 3 & 14,29 & $\begin{array}{c}\text { Ciudad Lineal } \\
\text { Fuencarral- El Pardo } \\
\text { Hortaleza }\end{array}$ \\
\hline $\begin{array}{c}\text { Clúster 3- } \\
\text { Distritos } \\
\text { con } \\
\text { impacto } \\
\text { muy } \\
\text { elevado }\end{array}$ & 1 & 4,76 & Centro & 1 & 4,76 & Centro & 8 & 38,10 & $\begin{array}{c}\text { Arganzuela } \\
\text { Centro } \\
\text { Chamartín } \\
\text { Chamberí } \\
\text { Moncloa- Aravaca } \\
\text { Retiro } \\
\text { Salamanca } \\
\text { Tetuán }\end{array}$ \\
\hline
\end{tabular}

Fuente: Elaboración propia a partir de datos de Airbnb y Fotocasa 
Tabla 5. Características de los distintos clústeres

\begin{tabular}{|c|c|c|c|c|c|c|}
\hline \multicolumn{7}{|c|}{$\mathrm{N}$ a de Apartamentos completos de Airbnb } \\
\hline & \multicolumn{2}{|c|}{ Clúster 1} & \multicolumn{2}{|c|}{ Clúster 2} & \multicolumn{2}{|c|}{ Clúster 3} \\
\hline & Media & $\begin{array}{l}\text { Coeficiente } \\
\text { de variación }\end{array}$ & Media & $\begin{array}{l}\text { Coeficiente } \\
\text { de variación }\end{array}$ & Media & $\begin{array}{l}\text { Coeficiente de } \\
\text { variación }\end{array}$ \\
\hline $\begin{array}{l}\text { Airbnb - no apartamentos } \\
17 / 01 / 18\end{array}$ & 126,47 & 0,85 & 600,67 & 0,23 & 6386 & - \\
\hline $\begin{array}{l}\text { Airbnb - no apartamentos } \\
14 / 01 / 19\end{array}$ & 148,82 & 0,84 & 658,67 & 0,25 & 6846 & - \\
\hline \multicolumn{7}{|c|}{ Na de Apartamentos completos de Airbnb/ $\mathrm{km}^{2}$} \\
\hline & \multicolumn{2}{|c|}{ Clúster 1} & \multicolumn{2}{|c|}{ Clúster 2} & \multicolumn{2}{|c|}{ Clúster 3} \\
\hline & Media & $\begin{array}{l}\text { Coeficiente } \\
\text { de variación }\end{array}$ & Media & $\begin{array}{l}\text { Coeficiente } \\
\text { de variación }\end{array}$ & Media & $\begin{array}{l}\text { Coeficiente de } \\
\text { variación }\end{array}$ \\
\hline $\begin{array}{l}\text { Airbnb - no apartamentos } \\
\text { por } \mathrm{km}^{2} \quad 17 / 01 / 18\end{array}$ & 6,24 & 1,20 & 91.25 & 0,43 & 1218,7 & - \\
\hline $\begin{array}{l}\text { Airbnb - no apartamentos } \\
\text { por } \mathrm{km}^{2} \quad 14 / 01 / 19\end{array}$ & 7,27 & 1,16 & 102 & 0,38 & 1306 & - \\
\hline \multicolumn{7}{|c|}{ Precio medio apartamentos completos de Airbnb } \\
\hline & \multicolumn{2}{|c|}{ Clúster 1} & \multicolumn{2}{|c|}{ Clúster 2} & \multicolumn{2}{|c|}{ Clúster 3} \\
\hline & Media & $\begin{array}{l}\text { Coeficiente } \\
\text { de variación }\end{array}$ & Media & $\begin{array}{l}\text { Coeficiente } \\
\text { de variación }\end{array}$ & Media & $\begin{array}{l}\text { Coeficiente de } \\
\text { variación }\end{array}$ \\
\hline $\begin{array}{l}\text { Airbnb - precio medio } \\
17 / 01 / 18\end{array}$ & 79,57 & 0,23 & 92,85 & 0,18 & 105,95 & - \\
\hline $\begin{array}{l}\text { Airbnb - precio medio } \\
14 / 1 / 2019\end{array}$ & 109,67 & 0,51 & 111,42 & 0,19 & 118,47 & - \\
\hline \multicolumn{7}{|c|}{ Precio del alquiler/m2 de los apartamentos de Fotocasa } \\
\hline & Media & $\begin{array}{l}\text { Coeficiente } \\
\text { de variación }\end{array}$ & Media & $\begin{array}{l}\text { Coeficiente } \\
\text { de variación }\end{array}$ & Media & $\begin{array}{l}\text { Coeficiente de } \\
\text { variación }\end{array}$ \\
\hline $\begin{array}{l}\text { Fotocasa - Precio del } \\
\text { alquiler/m2 en Enero } 2018\end{array}$ & 10,49 & 0,06 & 12,65 & 0,01 & 15,18 & 0,09 \\
\hline $\begin{array}{l}\text { Fotocasa - Precio del } \\
\text { alquiler/m2 en Enero } 2019\end{array}$ & 11,24 & 0,05 & 13,20 & 0,02 & 16,43 & 0,78 \\
\hline
\end{tabular}

Fuente: Elaboración propia a partir de datos de Airbnb y Fotocasa

En los mapas posteriores (ver Figuras 6, 7, 8 y 9) podemos ver reflejados los distintos distritos agrupados en función de los análisis clúster, lo que permite detectar qué distritos han registrado mayores valores promedio en las distintas variables. Se muestra que, en estos distritos, el impacto tanto de los alquileres turísticos de Airbnb (Figuras 6,7 y 8 ) como de los precios de los alquileres permanentes de Fotocasa (Figura 9), es mayor. Los resultados de los distintos indicadores, que se ven reflejados los mapas, permiten sugerir que un destino considere las plataformas colaborativas como uno de sus indicadores, para poder garantizar la sostenibilidad del destino a largo plazo. El ejemplo más evidente que se detecta es el del distrito Centro, que debido a sus valores extremos en la mayoría de las variables se sitúa en un único clúster en las agrupaciones de Airbnb. Este ejemplo puede observarse en los mapas, que permiten determinar zonas con distintos grados de impacto de Airbnb en función del número de apartamentos y el precio y, como ya se ha mencionado anteriormente, el distrito con mayor saturación sería el distrito Centro según el número de alojamientos y el precio de estos.

Por otra parte, habría que considerar otros distritos que han experimentado valores elevados en el resto de las agrupaciones. Por un lado, en función de la distribución de los 
alojamientos de Airbnb por $\mathrm{km}^{2}$, encontraríamos en el clúster 3: Chamberí y Salamanca. Además, en la agrupación de los precios de los alquileres permanentes de Fotocasa, se añaden al distrito Centro otros distritos como, Arganzuela, Chamartín, Chamberí, Moncloa-Aravaca, Retiro, Salamanca y Tetuán.

Considerando que muchos de los distritos mencionados en el párrafo anterior son distritos residenciales por excelencia, un exceso de masificación turística podría provocar daños irreversibles. Para evitar estos daños podría ser aprobada en Madrid una legislación de pisos turísticos similar a la de la ciudad de San Francisco y, así, el alquiler de estas viviendas en Airbnb quedaría prohibido y la gran mayoría volverían al mercado del alquiler residencial de larga duración (Lee, 2016; Wegmann y Jiao, 2017). Aun así, no se presenta como la única posibilidad para gestionar la saturación de alquileres turísticos en determinados destinos, ya que existen herramientas tecnológicas que podrían ayudar a limitar los alquileres y espacios, como es el uso del cooperativismo de plataforma, facilitando la participación de las partes interesadas para fomentar la rehabilitación urbana (Alfonso-Sánchez, 2016; Falcón-Pérez y Fuentes-Perdomo, 2019). Otra solución, podría ser la implementación de inteligencia artificial para la gestión de destinos, ya que actualmente existen territorios, como es el caso de Amsterdam, que están implementando algoritmos para la gestión del destino turístico en distintos ámbitos (gestión de alojamientos turísticos ilegales, gestión de espacios de estacionamiento en la ciudad, así como gestión de residuos) a fin de garantizar la sostenibilidad del destino (Gemeente Amsterdam, 1 de Julio de 2020a). Helsinki se ha unido a Ámsterdam, convirtiéndose en las dos primeras ciudades del mundo en lanzar un registro abierto de inteligencia artificial. En este registro, recogen de forma detallada en qué ámbitos están usando estas tecnologías y cómo funcionan sus algoritmos implementados (Helsinki, 1 de Julio de 2020). Pero de momento, Ámsterdam, es la única ciudad que recoge la implementación de algoritmos para localizar alquiler turístico ilegal. Este algoritmo apoya a los empleados del departamento de Vigilancia y Cumplimiento en la investigación de las denuncias realizadas sobre posibles alquileres vacacionales ilegales. El algoritmo ayuda a priorizar los informes de denuncias, para que las mismas se puedan utilizar de manera eficiente y eficaz. Al analizar los datos de casos relacionados con viviendas ilegales de los últimos 5 años, el algoritmo calcula la probabilidad de una situación de alquiler vacacional ilegal en la dirección informada (Gemeente Amsterdam, 1 de Julio de 2020b).

Por último, se observa en las distintas agrupaciones que en los distritos del clúster 1 de las agrupaciones de Airbnb, los efectos de Airbnb no han sido tan acusados como en el resto de los clústeres, causando distorsiones mínimas en el territorio. Además, estos distritos gozan de una capacidad territorial muy superior al resto de clústeres y el número de apartamentos de Airbnb en los mismos no es muy elevado, por lo que la intervención del Ayuntamiento madrileño se dirige a potenciar el turismo en algunas de estas áreas a través de acciones recogidas en el Plan Especial de Regulación del uso de Servicios Terciarios en la clase de Hospedaje ${ }^{1}$. El PEH propone una estrategia de descentralización de la ciudad, imitando el modelo de otras capitales europeas con mayor dispersión en sus viviendas turísticas, como Berlín, Ámsterdam o París. Debe considerarse que la capacidad de autogestión turística del destino tiene que ser una parte primordial de un destino turístico

\footnotetext{
${ }^{1}$ https://www.bocm.es/boletin/CM_Orden_BOCM/2019/04/23/BOCM-20190423-38.PDF
} 
inteligente, para evitar no sólo la masificación turística sino la gentrificación en determinados distritos.

Figura 6. Configuración de las agrupaciones de distritos en función de la cantidad de alojamientos completos de Airbnb de los distritos

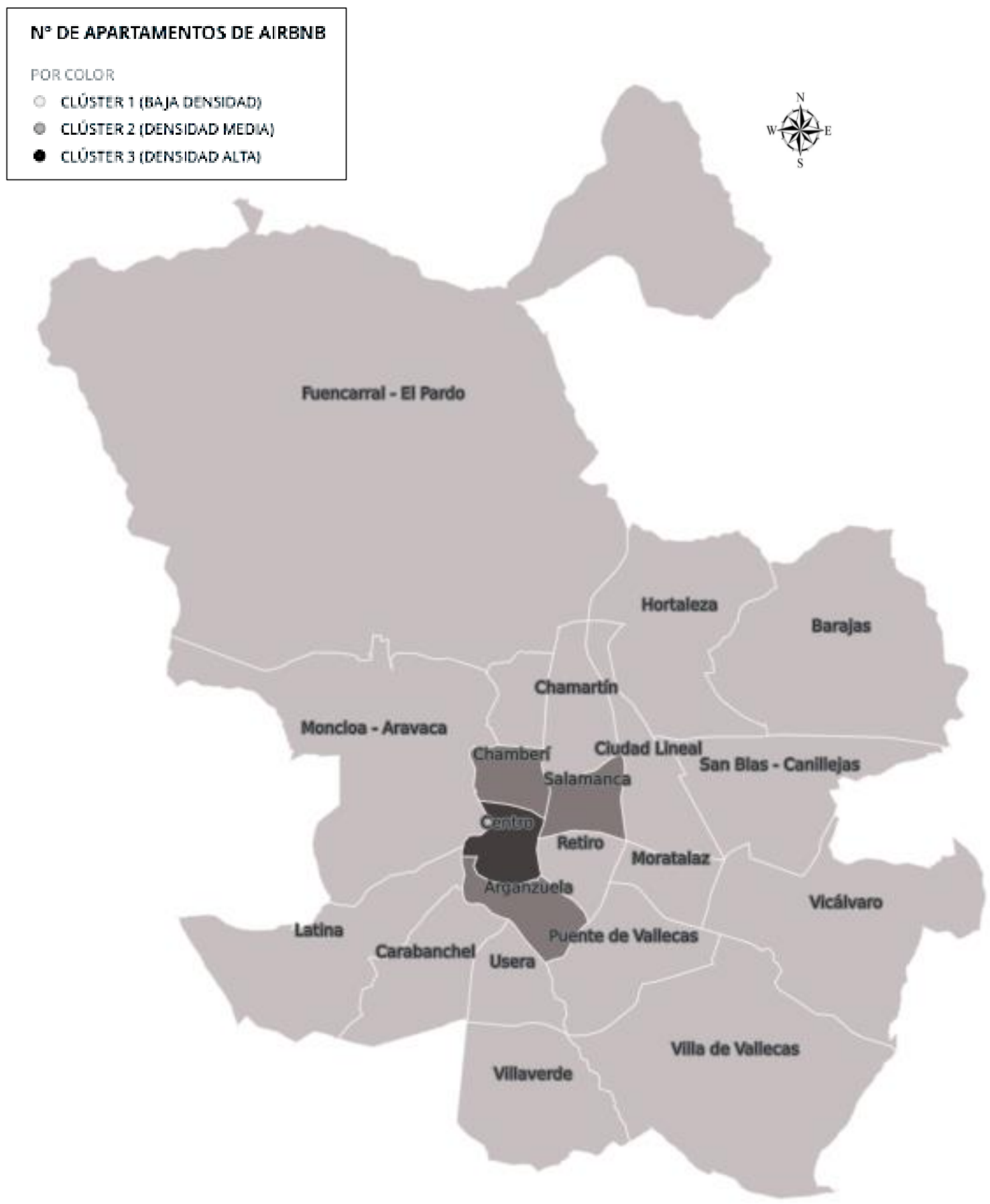

Fuente: Elaboración propia a partir de datos de Airbnb 
Figura 7. Configuración de las agrupaciones de los distritos en función del número de alojamientos completos de Airbnb por $\mathrm{km}^{2}$

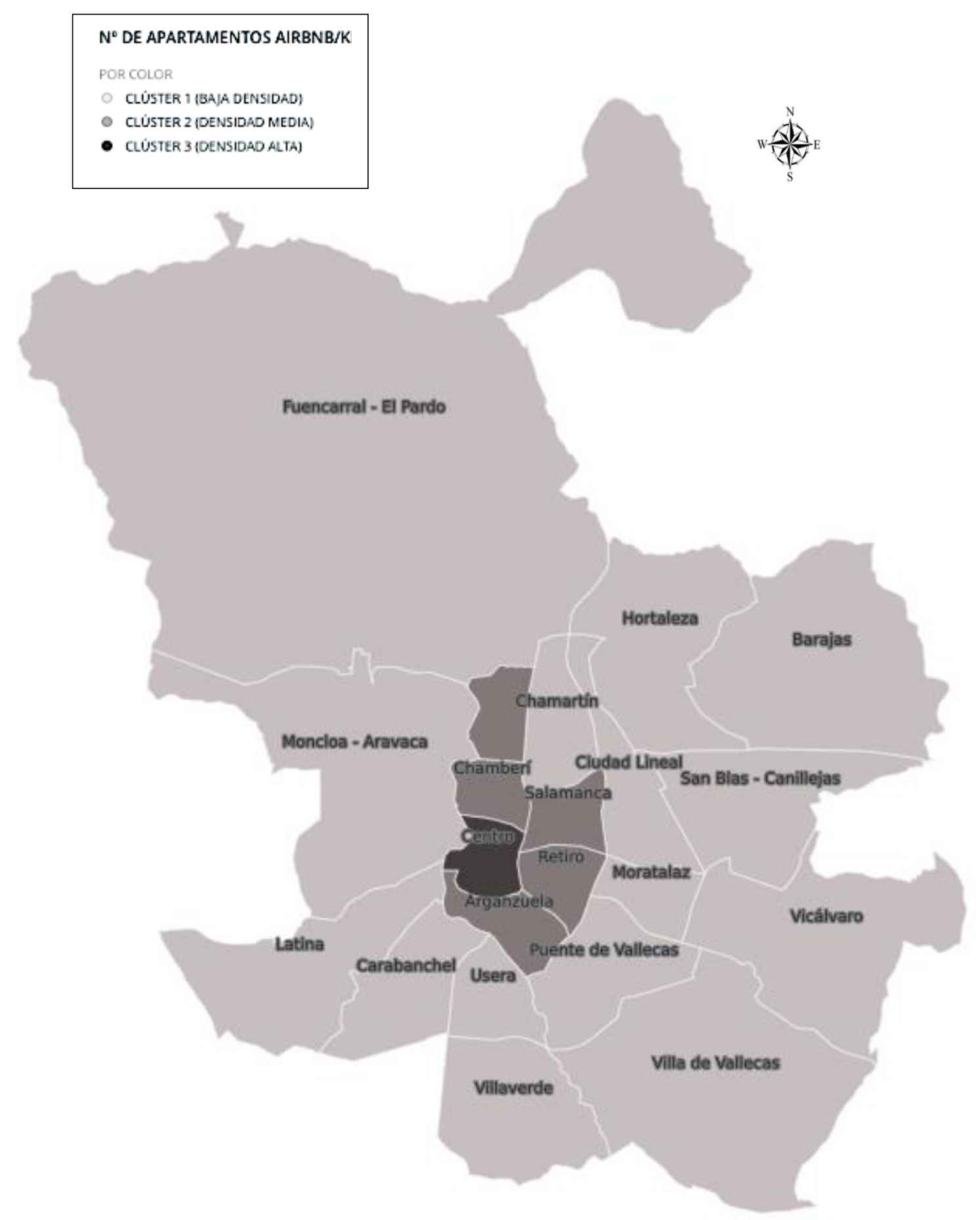

Fuente: Elaboración propia a partir de datos de Airbnb 
Figura 8. Configuración de las agrupaciones de distritos en función del precio medio que tienen los alojamientos completos de Airbnb en dichos distritos

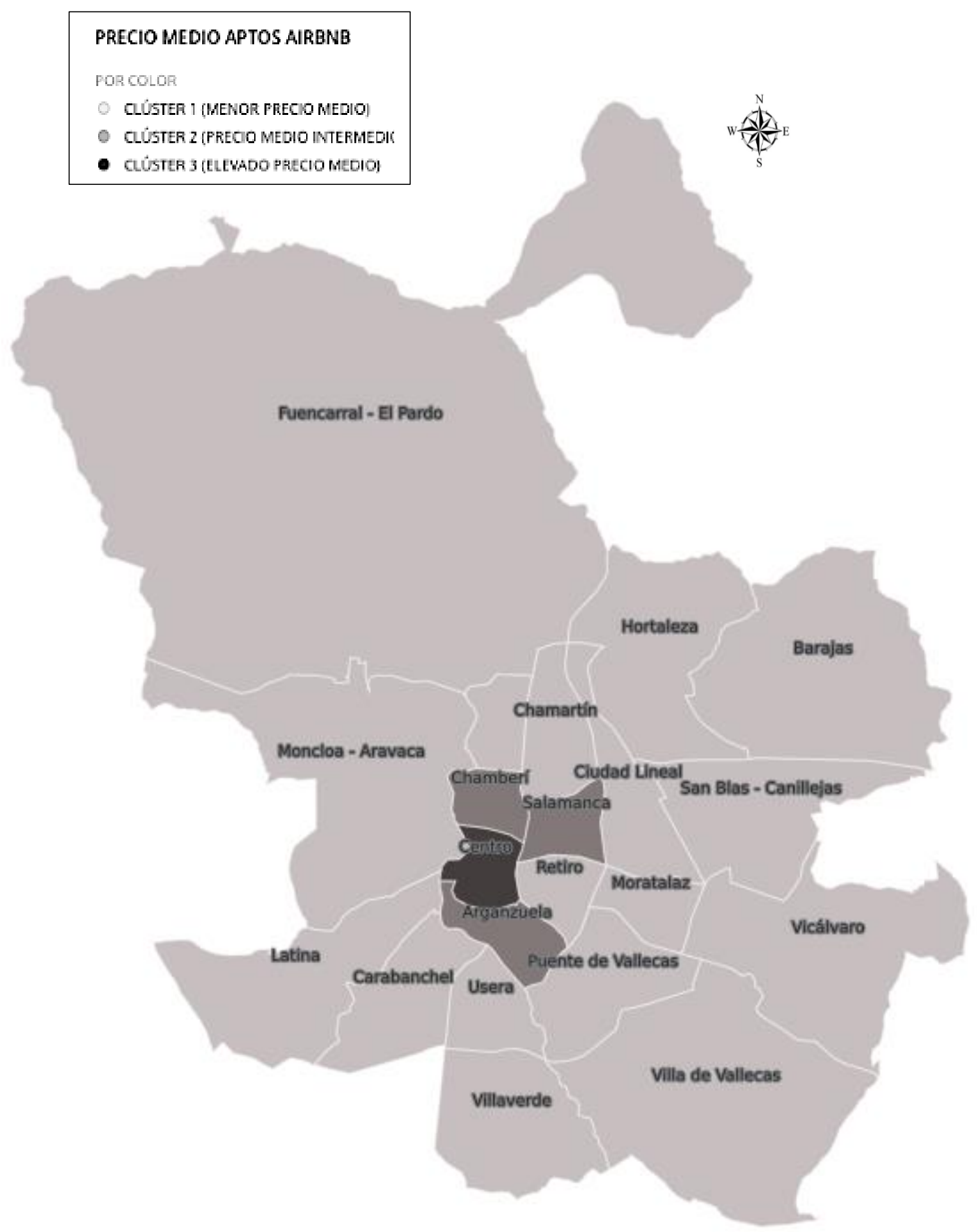

Fuente: Elaboración propia a partir de datos de Airbnb 
Figura 9. Configuración de las agrupaciones de distritos en función del precio de los alojamientos por $\mathrm{m} 2$ de Fotocasa de cada distrito

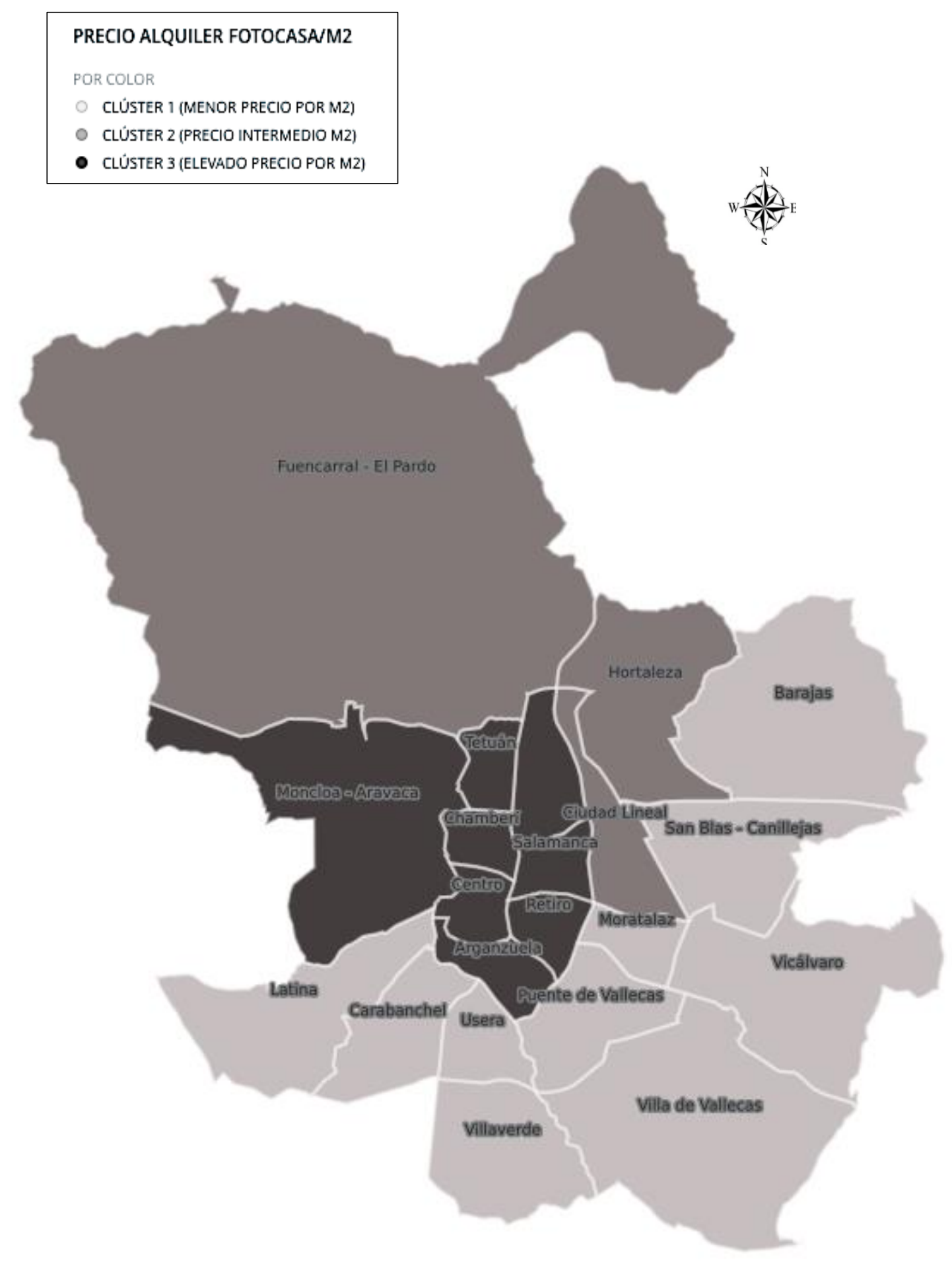

Fuente: Elaboración propia a partir de datos de Fotocasa 


\section{CONCLUSIONES}

La revisión de la literatura muestra que los estudios territoriales sobre el modelo de gestión turística de Airbnb adquieren cada vez más relevancia, si bien todavía no existe un número excesivo de artículos que se focalicen en este tema. El presente artículo quiere contribuir a la investigación, ofreciendo indicadores de alerta temprana para detectar zonas que sufren procesos de turistificación.

Gracias a los resultados de este estudio, nos permite responder a nuestra pregunta de investigación: ¿Los datos de los alojamientos de Airbnb pueden servir como indicadores de alerta temprana para detectar zonas que sufren procesos de turistificación?, mostrando la utilidad que podrían tener los datos de los alojamientos como indicadores, tanto a nivel turístico por parte de Airbnb, como a nivel residencial por parte de Fotocasa, y que podrían implementarse como indicadores de alerta temprana. Todos aquellos cambios que disrumpen en el destino y alteran significativamente la oferta y la demanda turística, tienen un impacto sobre el territorio que debe considerarse; como es el caso de plataformas colaborativas como Airbnb. Según Gil (2018), Airbnb tiene un fuerte impacto sobre los precios de los alquileres, los desplazamientos de la población local, la convivencia en el barrio y la transformación del comercio local. En definitiva, en el caso de Airbnb en Madrid, la oferta alojativa está en parte controlada por actores económicos profesionales (inmobiliarias, empresas especializadas, grandes y pequeños propietarios), cuya actividad consiste en extraer vivienda del mercado del alquiler para introducirla en Airbnb. Esto, no solo ocasiona un impacto en el mercado de alquiler y en el mercado de la vivienda, sino que además ocasiona un impacto en los barrios residenciales, convirtiéndolos en una atracción turística.

El caso del distrito Centro, es el caso más emblemático de la ciudad madrileña, como se ha evidenciado con los múltiples indicadores recogidos en el análisis clúster; este distrito requiere especial atención, ya que el número de apartamentos del distrito por km 2 es 10 veces superior al de cualquier otro distrito madrileño, por lo que dichos niveles de densidad podrían resultar insostenibles en el tiempo. Este argumento se encuentra en línea con los resultados que arrojan otras investigaciones, que exponen que Madrid practica un patrón de explotación intensiva, cuyo núcleo de actividad reside en el centro histórico, lugar donde hallan la mayor confrontación entre el alquiler residencial y el alquiler turístico (Martínez-Caldentey et al., 2020). Aún así, no es el único distrito que se encuentra afectado por el impacto de Airbnb, el resto de los distritos del segundo clúster: Arganzuela, Chamartín, Chamberí, MoncloaAravaca, Retiro, Salamanca y Tetuán; también presentan elevados valores en promedio de las variables estudiadas; añadiendo la consideración de que se tratan de barrios residenciales, por lo que la evolución de Airbnb en los mismos, influye directamente en la calidad de vida de los residentes y en el propio futuro de los destinos. Una de las posibles soluciones para descongestionar el distrito Centro y sus alrededores es el primer clúster, ya que está compuesto por distritos que se localizan en el extrarradio de la ciudad, pero cuya capacidad territorial para ofertar y acoger demanda turística es notablemente mayor.

Definitivamente deben evitarse los procesos turistificación en las ciudades (VergaraConstela y Casellas, 2016). Al hilo de esta propuesta, debe mencionarse que el Ayuntamiento de Madrid ha aprobado el PEH con el fin de llevar a cabo una estrategia de descentralización, que delimita la ciudad madrileña en anillos concéntricos para corregir y compensar la dinámica demostrada por el mercado. Es fundamental, recalcar el hecho de que Madrid cuenta con un buen sistema de transportes (Gschwender, 2007), lo que puede ser una pieza fundamental 
para posibilitar estas medidas de descentralización turística. Además, investigaciones parejas que apuntan resultados y reflexiones similares reflejando la necesidad de que los poderes públicos pongan en primer plano el bienestar social (Mansilla, Henche \& Devesa, 2021), por encima de la mercantilización turística de la vivienda, asegurando con ello el acceso a la vivienda a toda la población (Martínez-Caldentey et al., 2020). Es más, en el caso madrileño las investigaciones como la de Gil y Sequera (2020) llegan a apostar por una regulación que prohíba los listados comerciales, como lo han implementado ciudades como San Francisco. Eliminando los actores profesionales y los listados de impacto de la plataforma permitiendo solo aquellos hosts cuya actividad se lleve a cabo bajo los principios de la economía colaborativa. Añadiendo a la regulación madrileña un criterio territorial, para evitar que más de la mitad del mercado se concentre en una parte del territorio, lo que permitiría una mayor distribución territorial de la oferta.

Además de las estrategias propuestas por el propio Ayuntamiento de Madrid, se considera, tras reflexionar sobre los datos reflejados en el estudio, que podría ser recomendable el uso del cooperativismo de plataforma para fomentar la rehabilitación urbana (Falcón-Pérez y Fuentes-Perdomo, 2019), así como podría implementarse inteligencia artificial para gestionar el destino de forma eficaz y eficiente mediante el uso de algoritmos (De Carlo et al., 2020). Madrid, podría tomar de ejemplo la gestión de Ámsterdam, que como se ha comentado anteriormente, está implementando algoritmos para la gestión del destino turístico en distintos ámbitos (gestión de alojamientos turísticos ilegales, gestión de espacios de estacionamiento en la ciudad, así como gestión de residuos); así implementa mejoras que pueden favorecer la calidad de vida de los residentes y la sostenibilidad del propio destino.

Esta mejora en la gestión nos conduce a abrir nuevas líneas de investigación que relacionen la economía colaborativa o de plataforma con lo que se conoce como destinos turísticos inteligentes. Debe comprenderse que el concepto de turismo inteligente surgió en un contexto social y tecnológico, (Law et al., 2014; Benckendorff et al., 2014; Koo et al., 2015) entendido como la gestión de destinos innovadores, sustentados con tecnología de vanguardia que facilitan una experiencia excelente al turista y mejoran la calidad de vida del residente. En consecuencia, un destino turístico inteligente puede ser definido como un espacio consolidado sobre la base de un territorio que cuenta con una infraestructura tecnológica de vanguardia, la cual favorece el desarrollo sostenible, es accesible para todos los públicos, permite la integración e interacción del visitante con el entorno y mejora la calidad de su experiencia, así como incrementa la calidad de vida de los residentes (AENOR, 2013). La idoneidad de proponer un modelo futuro que combine los destinos turísticos inteligentes y la economía colaborativa (DTIC), podría permitir dirigir intercambios entre ambos hacia la sostenibilidad de los destinos mediante la gobernanza como eje regulador; satisfaciendo las necesidades presentes, protegiendo y mejorando las oportunidades del futuro de los destinos.

\section{REFERENCIAS BIBLIOGRÁFICAS}

AENOR (2013). Sub-comité de Normalización de los Destinos Turísticos Inteligentes. https://portal.aenormas.aenor.com/revista/pdf/abr16/10abr16.pdf

Aldenderfer, M. y Blashfield, R. (1984). Cluster Analysis. Series: Quantitative Applications in the Social Sciences. London: SAGE Publications. 
Alfonso-Sánchez, R. (2016). Economía colaborativa: un nuevo mercado para la economía social. CIRIEC-España, Revista de Economía Pública, Social y Cooperativa, 88, 231-258, https://doi.org/10.7203/CIRIEC-E.88.9255.

Ardura, A. (2017). La incidencia de la proliferación del alojamiento turístico en viviendas en el centro de Madrid. Ponencia para el Ber encuentro europeo Vivre le ville. Recuperado de: http://www.vivre-la-ville.fr/wp-con-tent/uploads/2017/03/VivreLaVille-Madrid2017 Po- nenciaTurismo-ES.pdf

Ardura, A. U., Lorente-Riverola, I., y Ruiz, J. S. (2020). Platform-mediated short-term rentals and gentrification in Madrid. Urban Studies, 57(15), 3095-3115. https://doi.org/10.1177/0042098020918154

Ashworth, G., y Stephen, J. (2011). Page. 2011. Urban tourism research: Recent progress and current paradoxes. Tourism Management, 32(1), 1-15. https://doi.org/10.1016/j.tourman.2010.02.002

Ayuntamiento de Madrid. Banco de datos. [En línea]. Recuperado de: https://www.madrid.es/portales/munimadrid/es/Inicio/El-

Ayuntamiento/Estadistica/Areas-de-informacion-estadistica/Territorio-climatologiay-medio-ambiente/Territorio/Mapas-de-Distritos-y-

Barrios/?vgnextfmt=default\&vgnextoid=240d64c49579f410VgnVCM1000000b205a0 aRCRD\&vgnextchannel=e59b40ebd232a210VgnVCM1000000b205a0aRCRD [Consulta 04/08/2020].

Ayuntamiento de Madrid (2017). La Oferta de Alojamiento Turístico en Madrid Características y Distribución Territorial. Área de Desarrollo Urbano Sostenible. Informe elaborado por la consultora Red2Red. Madrid: Ayuntamiento de Madrid.

Bailey, K. D. (1994). Typologies and taxonomies: An introduction to classification. Thousand Oaks: Sage.

Benckendorff, P. J., Sheldon, P. J., y Fesenmaier, D. R. (2014). Social media and tourism. Tourism information technology, 120147. https://doi.org/10.1079/9781780641850.0120

Calle, M. (2019). Turistificación de centros urbanos: clarificando el debate. Boletín de la Asociación de Geógrafos Españoles, 83, 2829, 1-40. http://dx.doi.org/10.21138/bage.2829

Cocola-Gant, A. (2016). Holiday rentals: The new gentrification battlefront. Sociological Research Online, 21(3), 1-9. https://doi.org/10.5153/sro.4071

Cocola-Gant A y López-Gay A (2020) Transnational gentrification, tourism and the formation of 'foreign only' enclaves in Barcelona. Urban Studies (in press). https://doi.org/10.1177/0042098020916111.

Cummings, J. (2015). Confronting favela chic: the gentrification of informal settlements in Rio de Janeiro, Brazil. Global gentrifications: Uneven development and displacement, 8199. 
De Carlo, M., Ferilli, G., D'Angella, F. y Buscema, M. (2020). Artificial intelligence to design collaborative strategy: An application to urban destinations. Journal of Business Research. https://doi.org/10.1016/i.jbusres.2020.09.013

Diario de Madrid (2017). Madrid, 21 distritos que nos hacen un gran destino [En línea]. Recuperado de: https://diario.madrid.es/blog/notas-de-prensa/madrid-21-distritosque-nos-hacen-un-gran-destino/

Dudás, G., Boros, L., Kovalcsik, T., y Kovalcsik, B. (2017). The visualisation of the spatiality of Airbnb in Budapest using 3-band raster representation. Geographia Technica, 12(1), 23-30. https://doi.org/10.21163/GT 2017.121.03

ECM (2020). The ECM Benchmarking Report 2019-2020. Recuperado de: https://www.europeancitiesmarketing.com/ecm-benchmarking-report/

Falcón-Pérez, C.E. y Fuentes-Perdomo, J. (2019). Mejorando el bienestar de la sociedad a través del cooperativismo de plataforma. CIRIEC-España, Revista de Economía Pública, Social y Cooperativa, 95, 161-190, https://doi.org/10.7203/CIRIEC- E.95.12655.

Fendéu BBVA (2017). Turistificación, neologismo válido. Recuperado de: https://www.fundeu.es/recomenda- cion/turistificacion-neologismo-valido/. [18-042020].

Gemeente Amsterdam (1 de Julio de 2020a). Algorithmic systems of Amsterdam City of Amsterdam Algorithm Register Beta. https://algoritmeregister.amsterdam.nl/en/airegister/

Gemeente Amsterdam (1 de Julio de 2020b). Illegal holiday rental housing risk. City of Amsterdam Algorithm

Register Beta. https://algoritmeregister.amsterdam.nl/en/illegal-holiday-rental-housing-risk/

Gil, J. (2018, 9 de enero). El conflicto de Airbnb aterriza sobre Madrid (1a parte). Diario Público. Recuperado de: http://blogs.publico.es/contrapar- te/2018/01/09/el-conflicto-deairbnb-aterriza-sobre- madrid-1a-parte/

Gil, J. (2018). ¿Cómo regular el hospedaje entre particulares? Criterios de regulación utilizando el caso de Airbnb. En A. M. de la Encarnación (Eds.), La regulación del alojamiento colaborativo. Viviendas de uso turístico y alquiler de corta estancia en el Derecho español. Thompson-Reuters Aranzadi.

Gil, J. y Sequera, J. (2018). Expansión de la ciudad turística y nuevas resistencias. El caso de Airbnb en Madrid. Empiria. Revista de metodología de ciencias sociales, (41), 15-32.

Gil, J., y Sequera, J. (2020). The professionalization of Airbnb in Madrid: Far from a collaborative economy. Current Issues in Tourism, 1-20.

González, S., y Waley, P. (2013). Traditional retail markets: the new gentrification frontier? Antipode, 45(4), 965-983. https://doi.org/10.1111/j.14678330.2012.01040.x

Gschwender, A. (2007). A Comparative Analysis of the Public Transport Systems of Santiago de Chile, London, Berlin and Madrid: What can Santiago learn from the European Experiences? (Doctoral dissertation, Universität Wuppertal, Fakultät für Architektur und Bauingenieurwesen» Bauingenieurwesen» Dissertationen). 
Gurran, N. y Phibbs, P. (2017). When tourists move in: how should urban planners respond to Airbnb?. Journal of the American planning association, 83(1), 80-92. https://doi.org/10.1080/01944363.2016.1249011

Helsinki (1 de Julio de 2020). Artificial intelligence systems of Helsinki. City of Helsinki Al Register. https://ai.hel.fi/en/ai-register/

Horn, K. y Merante, M. (2017). Is home sharing driving up rents? Evidence from Airbnb in Boston. Journal of Housing Economics, 38, 14-24. https://doi.org/10.1016/j.jhe.2017.08.002

INE (2019a) Cuenta satélite del turismo de España. Año 2019. Recuperado de: https://www.ine.es/dyngs/INEbase/es/operacion.htm?c=estadistica C\&cid=1254736 $169169 \&$ menu $=u \mid t i D a t o s \& i d p=1254735576863$

INE (2019b) Estadística de Movimientos Turísticos en Fronteras (FRONTUR). Año 2019. Recuperado de: https://www.ine.es/daco/daco42/frontur/frontur1219.pdf

Janoschka, M., y Sequera, J. (2016). Gentrification in Latin America: addressing the politics and geographies of displacement. Urban Geography, 37(8), 1175-1194. https://doi.org/10.1080/02723638.2015.1103995

Knafou, R. (1996). Turismo e territorio. Por uma abordagem científica do turismo. In A.A.B. Rodrigues. (Org.), Turismo e Geografía. Reflexoes teóricas e enfoques regionais (pp. 62-75). Sao Paulo: Editora Hucitec.

Ketchen, D. y Shook, C. (1996). The application of cluster analysis in strategic management research: an analysis and critique. Strategic Management Journal, 17, pp. 441-458. https://doi.org/10.1002/(SICI)1097-0266(199606)17:6<441::AID-SMJ819>3.0.CO;2-G

Kokalitcheva, K. (2015). Here's How Airbnb Justifies its Eye-Popping \$24 Billion Valuation, Time Inc. [En línea]. Recuperado de: http://fortune.com/2015/06/17/airbnb-valuationrevenue/ [Consulta 04/06/2020].

Koo, C., Gretzel, U., Hunter, W. y Chung, N. (2015). The role of IT in tourism. Asia Pacific. Journal of Information Systems, 25 (1): 99-104. https://doi.org/10.14329/apjis.2015.25.1.099

Lalicic, L., y Weismayer, C. (2017). The role of authenticity in Airbnb experiences. In Information and communication technologies in tourism 2017 (pp. 781-794). Springer, Cham. https://doi.org/10.1007/978-3-319-51168-9 56

Law, R., Buhalis, D., y Cobanoglu, C. (2014). Progress on information and communication technologies in hospitality and tourism. International Journal of Contemporary Hospitality Management, 26 (5), 727-750. https://doi.org/10.1108/IJCHM-08-2013$\underline{0367}$

Leal, J. (2004) Segregation and social change in Madrid metropolitan region. The Greek Review of Social Research 113: 81-104. https://doi.org/10.12681/grsr.9219

Lee, D. (2016). How Airbnb short-term rentals exacerbate Los Angeles's affordable housing crisis: Analysis and policy recommendations. Harv. L. \& Pol'y Rev., 10, 229.

Madrid Destino. [En línea]. Recuperado de: https://www.madrid-destino.com/turismo [Consulta 3/08/2020]. 
Mansilla, E. C., Henche, B. G., \& Devesa, M. J. S. (2021). Análisis de la economía colaborativa en el turismo urbano. Estudio de la implantación de Airbnb en Madrid y Barcelona. Cuadernos de Turismo, 383-412. https://doi.org/10.6018/turismo.474481

Martínez-Caldentey, M. A., Murray, I. y Blázquez-Salom, M. (2020). En la ciudad de Madrid todos los caminos conducen a Airbnb. Investigaciones Turísticas (19), 1-27. https://doi.org/10.14198/INTURI2020.19.01

Navarro, P. y Vejsberg L. (2009). El proyecto turístico Barilochense antes de Bustillo. Entre la prehistoria del Parque Nacional Nahuel Huapi y el desarrollo local. Estudios y Perspectivas en Turismo, 18, pp. $414-433$. Buenos Aires, Argentina

Nofre, J., Giordano, E., Eldridge, A., Martins, J., y Sequera, J. (2018). Tourism, nightlife and planning: challenges and opportunities for community liveability in La Barceloneta. Tourism Geographies, 20(3), 377-396. https://doi.org/10.1080/14616688.2017.1375972

Notatrasnota.com. ITB Berlin e IPK International revelan cómo le va a World Travel. [En línea]. Disponible en: https://notatrasnotacom.wordpress.com/2019/11/20/itbberlin-e-ipk-international-revelan-como-le-va-a-world-travel/ [Consulta 3/09/2019].

Pixová, M., y Sládek, J. (2017). Touristification and awakening civil society in post-socialist Prague. Protest and resistance in the tourist city, 73-89.

Porras, S., y García Castaño, J. (2016, 10 de diciembre). Viviendas de uso turístico: la gran recali- ficación. Eldiario.es. Recuperado de: https://www.eldiario.es/opinion/tribunaabierta/viviendas-uso-turistico-gran-recalificacion 129 3691942.html

Rodríguez-Antón, J.M., Alonso-Almeida, M.M., Rubio-Andrada, L. y Celemín-Pedroche, M.S. (2016). La economía colaborativa. Una aproximación al turismo colaborativo en España. CIRIEC-España, Revista de Economía Pública, Social y Cooperativa, 88, 259-283.

Santos, J. A., y Sequera, J. (2018). Expansión de la ciudad turística y nuevas resistencias: el caso de Airbnb en Madrid. Empiria: Revista de metodología de ciencias sociales, (41), 15-32.

Sequera, J. y Nofre, J. (2018). Shaken, not stirred: New debates on touristification and the limits of gentrification. City, 22(5-6), 843855.https://doi.org/10.1080/13604813.2018.1548819

Sequera, J. y Nofre, J. (2019) Touristification, transnational gentrification and urban change in Lisbon: The neighbourhood of Alfama. Urban Studies. Epub ahead of print 17 December 2019. https://doi.org/10.1177/00420980 19883734.

Slee, T. (2019) "Airbnb Data Collection: Get the data". Recuperado de: http://tomslee.net/airbnb-data-collection-get-the-data (Último acceso: 10-05- 2020)

Sorando, D. y Ardura, Á. (2016) First we take Manhattan: La destrucción creativa de las ciudades. Madrid, Catarata.

Vergara-Constela, C. y Casellas, A. (2016). Políticas estatales y transformación urbana: ¿hacia un proceso de gentrificación en Valparaíso, Chile? EURE (Santiago), 42(126), 123-144. https://doi.org/10.4067/S0250-71612016000200006 
Vestri, G. (2020). Acceso a la vivienda en la época de la "gentrificación» y de la «turisficación». El distrito casco antiguo de Sevilla como caso de estudio: legislaciones administrativas a prueba. Dereito: revista xurídica da Universidade de Santiago de Compostela, 29(Ext).

Wegmann, J. y Jiao, J. (2017). Taming Airbnb: Toward guiding principles for local regulation of urban vacation rentals based on empirical results from five US cities. Land use policy, 69, 494-501. https://doi.org/10.1016/j.landusepol.2017.09.025

World Economic Forum. The Global Competitiveness Report 2019. [En línea]. Recuperado de: http://www3.weforum.org/docs/WEF TheGlobalCompetitivenessReport2019.pdf [Consulta 3/5/2020].

Yrigoy, I. (2017). Airbnb in Menorca: a new form of touristic gentrification? Distribution of touristic housing dwelling, agents and impacts on the residential rent. Scripta NovaRevista Electrónica de Geografía y Ciencias Sociales, 21(580). https://doi.org/10.1344/sn2017.21.18573

21 distritos (2021). Programación cultural del Ayuntamiento de Madrid. [En línea]. Recuperado de: https://21distritos.es/ [Consulta 12/07/2021].

\section{CONTRIBUCIÓN DE LOS AUTORES:}

Autor 1: Concepción original del trabajo, definición, integración y redacción de los apartados.

Autor 2: Análisis crítico de los apartados. Supervisión de la redacción y coherencia del artículo. Aprobación final de la versión a publicar.

Autor 3: Análisis crítico de los apartados. Supervisión de la redacción y coherencia del artículo. Aprobación final de la versión a publicar.

Autor 4: Análisis crítico de los apartados. Supervisión de la redacción y coherencia del artículo. Aprobación final de la versión a publicar.

\section{AGRADECIMIENTOS:}

Este trabajo fue apoyado por el Ministerio de Universidades mediante el contrato [FPU2018 / 05131] y por las Ayudas a la Investigación del 2020-2021 de la Fundación Banco Sabadell. Paralelamente recibió apoyo de dos proyectos del Ministerio de Ciencia e Innovación de España: PID2020-113561RB-I00 y PID2020-114788RB-I00 